\title{
Code Creation in Endogenous Merger Experiments
}

\author{
Lauren Feiler and Colin F. Camerer \\ Division of Humanities and Social Sciences \\ California Institute of Technology \\ Pasadena, CA 91125 USA \\ lauren@hss.caltech.edu \\ camerer@hss.caltech.edu
}

\begin{abstract}
:
We study the difficulty that can be caused by firms' use of specialized language, or code, when organizations merge, and whether participants' valuations of mergers take this difficulty into account. The experiments use a picture-naming paradigm. Subjects are grouped into "firms," separately at two universities, and create code words to describe a series of pictures from their own college campus, rapidly and clearly. The codes are a component of "organizational culture," which can be created rapidly and has efficiency properties. After creating a shared code, subjects from two firms are placed into a merged group, based on payments they demand to join that group, and must name a mixture of pictures from both campuses. The bids both allow self-selection and enable a test of whether subjects who join the merged group underestimate the difficulty of code integration. Performance clearly decreases in the merged firm because of differences in code and unfamiliarity with pictures of the other campus. Guesses by all subjects about post-merger performance, and the values of low bidders revealed by Vickrey auctions and inferred from first-price auction bids, underestimated the difficulty of merger on average. Inferred values overall indicate fairly accurate guesses about the difficulty of integration, but the lowest values (corresponding to those who actually join the merger) are too optimistic, reflecting an "organizational winner's curse." In a second merger phase, however, guesses and bids are more accurate (but slightly pessimistic), which indicates a capacity to learn to use code in merged groups from one merger event to another, and to forecast more accurately from one merger to the next.
\end{abstract}

February 9, 2006. This research was supported by discretionary research funds from Caltech to Colin Camerer. We are grateful to Galen Loram, Ming Hsu, Charlie Hornberger, John Lin, and Joseph Wang for going above and beyond the call of duty to make sure this project worked. We also benefited from helpful discussions with Preston McAfee, Simon Wilkie, and Paul Healy, and comments from audiences at Caltech, Chicago GSB, ESA, and the Behavioral Organizational Economics meeting at MIT. 


\section{Introduction}

Corporate culture is the value system, symbols, ideas, icons, stories, and language that express the informal contracts between a firm and its employees, customers, and suppliers - "how business is done" at a company. Conflicts in corporate culture appear to contribute to merger failures, but there is little systematic research on this topic. The scarcity of attention paid to conflicts that affect billion-dollar transactions may be partly due to the difficulty of operationalizing the vague concept of corporate culture precisely.

In this paper, we focus on one very simple component of culture that can be created experimentally and measured clearly — the code, or specialized language used within a firm. Code is one facet of culture and also has some of the properties of other facets (e.g., values and symbols): Code can be productive by coordinating activity, is usually durable, and is often pathdependent and difficult to recreate or copy. To study code creation, we create simple "firms" in a laboratory setting, and use a picture-naming paradigm (Weber and Camerer, 2003) in which they develop code. We then examine the impact on performance when two firms with specialized codes for different pictures are merged together. We are also interested in other features of a merger, such as perceptions of how difficult mergers are, and the endogenous choice of whether to join the merger, and we measure these phenomena by having subjects bid for extra payments to join the merger.

These experimental organizations are highly stylized and simple. But their simplicity gives us precision in measuring variables and understanding the determinants of performance. In the experimental world, the code words subjects use are their culture; the money they earn is their organizational performance. Furthermore, the experiments are simply a platform onto which complications can be built, as theory suggests what complications are most interesting. 
We learn the most in any empirical science from a series of experiments, which cumulate into regularity. The earliest experiments in any series will necessarily be the simplest (just as theory develops from simple to more complex). Therefore, criticism of the simplicity of the design is most useful when it comes in the form of a suggestion for an enriched design (provided it is feasible) and a conjecture about how the enrichment will change behavior.

\section{a. Merger Failure}

Although mergers are often met with excitement on Wall Street and in the boardroom, there is ample evidence that acquiring firm shareholders often lose from mergers (e.g. Andrade, Mitchell, and Stafford, 2001). Most of these studies use stock market returns in a short window of time around the merger announcement, so they rely on the hypothesis that the stock market guesses future merger success accurately. By using only returns it is impossible to tell whether mergers actually generate anticipated economic synergies years later, and whether acquiring firms overpay even if synergies do result.

In careful studies using FTC Line-of-Business data to compare acquired firms to similar firms that did not merge, Ravenscraft and Scherer $(1987,1989)$ find that on average, acquired firms are less profitable than before the acquisition, and mergers often result in later divestitures. The high turnover rates that accompany mergers are frequently attributed to firing poor managers in the acquired firm, but the best managers are actually the ones who are most likely to leave in the first year after a merger (Walsh and Ellwood, 1991; Walsh, 1988).

Some of the problems that occur when firms merge can be attributed to clashes in the culture of the firm. A 1992 Coopers and Lybrand study on the largest acquisitions in the United Kingdom from the late 1980s to the early 1990s found that the executives surveyed considered 
54 percent of the acquisitions to be failures. Target management attitudes and cultural difference was the most widely-cited cause of merger failure; 85 percent of those surveyed listed it as a key factor. (Sudarsanam, 1995)

Firms often seem to underforecast how differing ways of doing business can prevent the imagined synergies of a merger. Sony, known for its innovative consumer electronics, branched into the entertainment industry in the late 1980's and early 1990's, acquiring firms like CBS Records and Columbia Pictures. Now, conflicts of interest between the electronics and entertainment divisions stymie the development of popular products, such as portable music players that allow audio files to be easily transferred from computers. Sony's electronics division is home to such revolutionary products as the Walkman and the most successful transistor radio, and its developers would be expected to lead the way in creating groundbreaking digital media devices. But the entertainment division is part of an industry with a long history of battling anything that could potentially foster piracy, such as CDs and VCRs. The entertainment side of Sony insists on copy protection mechanisms that make the products developed by the electronics division too cumbersome to be widely sold. Sony has even produced a music CD that could not be read on its own computers. The opposing value systems at the two warring sides of Sony prevent each division from profiting as much as they likely would on their own. (Rose, 2003) Given the difficulty of realizing the synergies between entertainment and electronics, it makes little economic sense to have those two divisions combined under one corporate roof.

The AOL-Time Warner merger is a "perfect storm" in which many factors, including culture, combined to create an unsuccessful merger (see Klein, 2003). Time Warner employees valued a "best in class" structure, in which each division strove to be the best compared to other 
companies in its field. Under this structure, each division essentially operated as its own separate firm. There was little communication between different divisions, and few successful joint projects. Being unused to this independence, $\mathrm{AOL}$ employees were appalled at being charged for services by a division of AOL-Time Warner. In turn, genteel Time Warner workers were disgusted at the crass language AOL employees would use in the boardroom and even with clients. AOL employees had developed a reputation for shouting at and exploiting clients (defrauding advertisers on AOL), in sharp contrast to Time Warner's polite business etiquette and old-school decorum. Although the cultures of AOL and Time Warner were bound to clash, the CEO's who engineered the merger and the boards who approved it did not seem to acknowledge this possible clash or its effects. In April 2002, accounting rules requiring firms to recognize declines in stock values after mergers led to a $\$ 54$ billion write-off, the largest corporate loss in U.S. history. In December 2004 Time Warner (which shed the "AOL" part of its name in 2003) paid $\$ 510$ million to settle accounting fraud allegations at AOL.

\section{b. Code}

Given the tremendous impact culture can have on firms' ability to successfully integrate, we would like to gain a better understanding of cultural conflict in a merged firm, and learn whether participants anticipate that conflict. But a full-blown culture cannot be created overnight, much less in a short experimental session. One aspect of culture, however, can be quickly developed - the language used to communicate within a firm. We call the language component of culture "organizational code." Codes are sets of words or phrases that are used to efficiently convey information within an organization. Code allows members of an organization to describe aspects of their complex environment and reduce the costs of communication. 
(Arrow, 1974; Crémer, Garicano, and Prat, 2004; Wernerfelt, 2004) It typically develops as members of an organization interact over time, and it is therefore unlikely to be easily understood by outsiders.

The use of codes and jargon in organizations is commonplace. To a cop, "11-27" means "subject has a felony record but is not wanted"; in a fast-moving kitchen, "give it some radar love" is an instruction to microwave a dish; air traffic controllers call the holding area for planes whose arrival gates are occupied the "penalty box" (which is an actual box in hockey). In all these situations, the members of the organization know the code and use it to quickly communicate with each other. Besides coordinating activity rapidly and clearly, code serves other organizational purposes. Code can: inspire (“just do it!"); identify who is in a group and who isn't; relieve tension ("circling the drain" is emergency room slang for a patient who has suddenly taken a turn for the worse, "code brown" for a bed with excrement); identify villains ("Larry Parker syndrome", a patient complaining of pain who is looking for an insurance settlement); and sanitize tragedy (“collateral damage”, military slang for civilian casualties).

Although efficient code normally takes a while to develop, it can be created quickly. People working on a project together may choose to create a common set of definitions that they will use throughout the task. (Crémer, Garicano, and Prat, 2004) Even robots have been found to quickly develop code, in an artificial intelligence experiment in which robots equipped with video cameras took turns describing what they "saw" to the other robot, which had to guess the object being described. Words that had been used successfully with the most frequency became the ones that would always be used to describe a certain object. (Steels, 2003)

Organizational culture is obviously more than code, but code is a good place to start because it can be created so rapidly, and has many similarities to the larger concept of culture. 
Although definitions of organizational culture vary, it is generally described as a shared social understanding among members of an organization, resulting in commonly held assumptions and views of the world. (Weber, Rick, and Camerer, 2004; Schein, 1985, 1990, Crémer, 1993) In economic terms, culture allows members of an organization to tacitly coordinate actions and provides guidelines for behavior under unforeseen change. (Kreps, 1990) Language plays an important role in culture because it restricts what can be communicated and shapes the way people think. Language also reflects the shared values and beliefs of a society or organization. (Weber, Rick, and Camerer, 2004)

In recent theory, organizational code is created out of the need for rapid, clear communication between group members. More precise or longer messages provide more information, but they cost more to communicate than shorter messages do. (Crémer, Garicano, and Prat, 2004; Wernerfelt, 2004) In our study, laboratory firms will have to develop code to do well in a task that rewards speed and accuracy.

\section{The Picture-Naming Paradigm}

We use the picture-naming paradigm introduced in experimental economics by Weber and Camerer (2003) to examine the problems that can arise in a merger based on lack of a common code. ${ }^{1}$ In our experiment, groups of people behave as a firm, with one manager and several employees working to accomplish a task. In every round of this task, each person in a group sees a set of eight pictures. Everyone in a group sees the same pictures, but they are

\footnotetext{
${ }^{1}$ Our experiment has several innovations beyond Weber and Camerer's. They used a single set of pictures so differences in group code were modest. By using two groups of students from different campuses, we generated a more natural and large variation in code and expertise. They forced mergers. We allowed self-selection into the merged firms, which enables us to detect an optimistic bias in bids, and a winner's curse among low bidders. Our computerized interface also allows more precise measurement of time and code.
} 
displayed in different configurations on each person's screen. The manager is privately informed about a subset of target pictures and must describe these pictures to the employees who don't know which pictures are targets. Employees must correctly identify each picture. Incorrect guesses are penalized and earnings are reduced by a multiple of the amount of time taken to name all four pictures. In order to earn money, the laboratory "firms" must develop a shared language to quickly and accurately identify each picture - they create code.

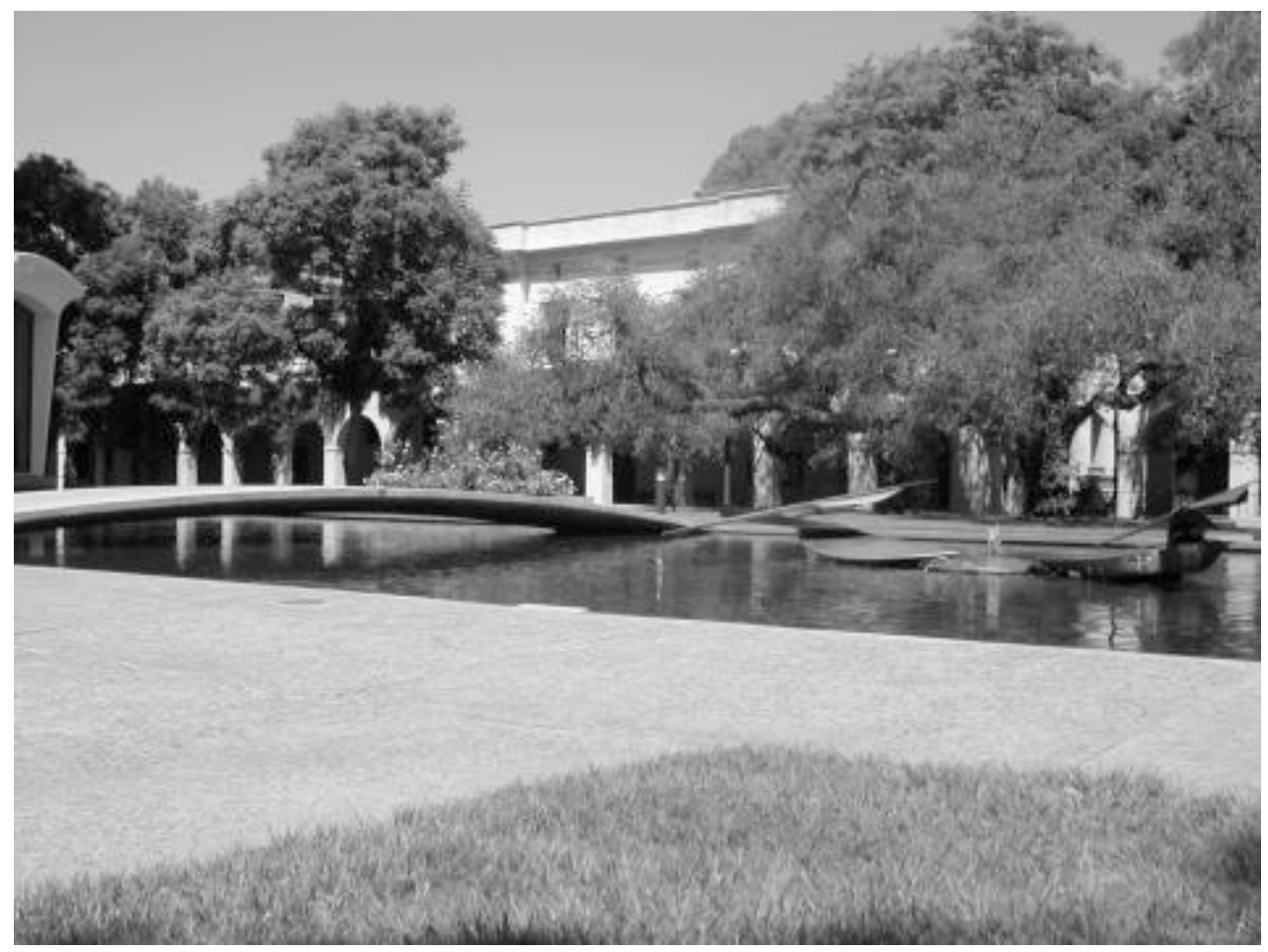

Figure 1. Picture from Caltech campus.

The design is meant to have central features of a typical horizontal or diversifying merger, in which two firms who make related products, but have differences in culture and code, merge and must coordinate activity. To create differences, and challenging mergers, we make use of the fact that a typical student is an expert on his school environment. To create natural 
cultural differences (and potentially, conflict) we use students at both UCLA and Caltech participating simultaneously through the web. The picture sets contain images of buildings, fountains, and other features of both the UCLA and Caltech campuses. Some of the code groups use has already been created, since there are proper names or slang for most of the buildings and landmarks seen in the pictures. But separate groups at Caltech and at UCLA do not all use the same code for each picture. For example, the image from the Caltech campus pictured in Figure 1 was coded as "Millikan bridge," "Millikan pond," "arch bridge," and "bridge over pond" by various groups at Caltech.

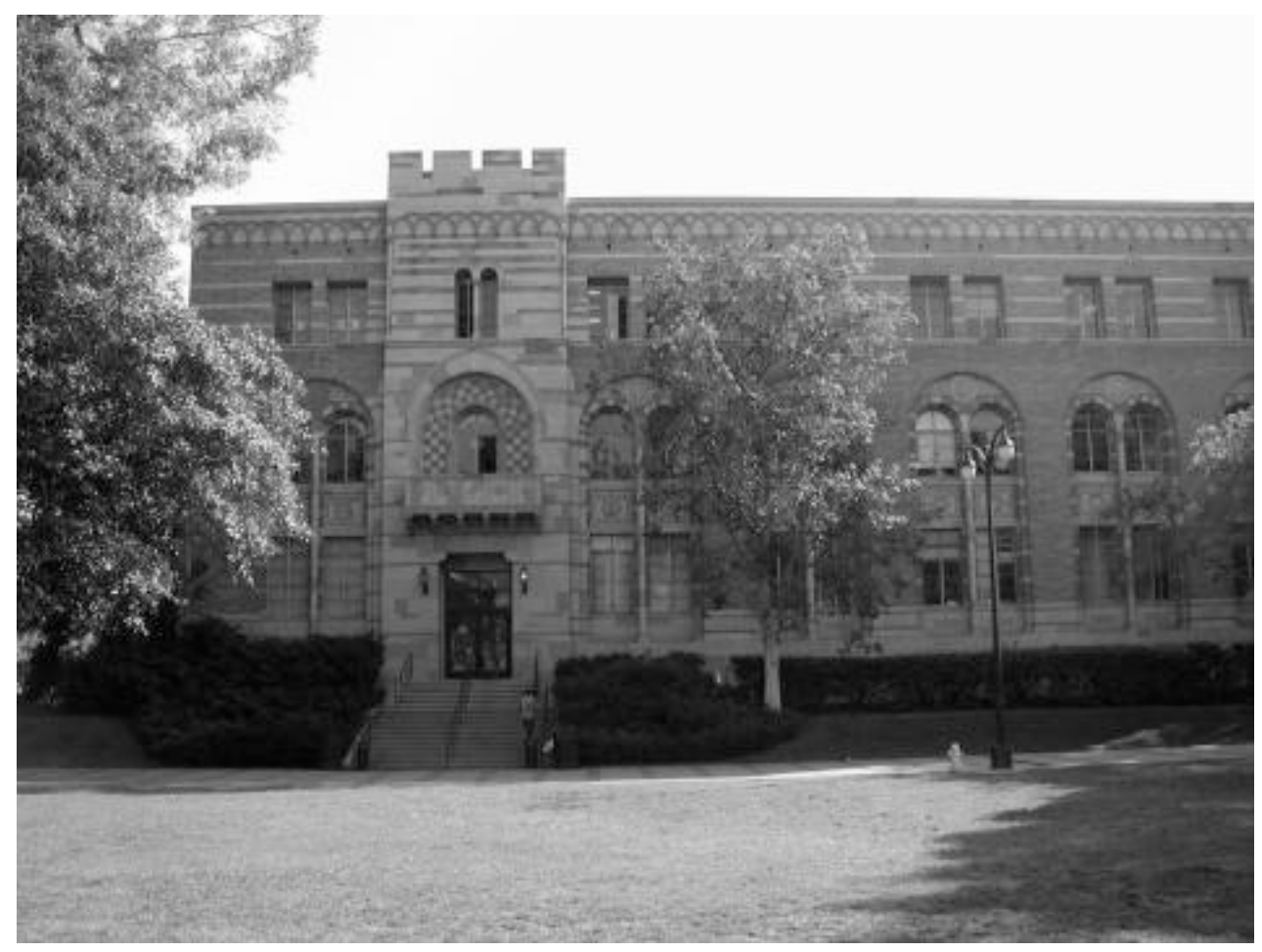

Figure 2. Picture from UCLA campus.

Within each group, the code used for a picture would evolve over many rounds. For one group at UCLA, the first description of the image in Figure 2 was "rectangle; its a flat building; with one tree; looks like haines; grass in front; its not that hard." [sic, semi-colons indicate 
separate lines of type] The second description of this image (from a different manager in the group) was shorter: "rectangular with grass in front; looks like castle; 2 trees." The third description was "rectangle closer up [to contrast to another building described as a rectangle]; with trees." Eventually, the group quickly identified this image as "rect, castle" or simply “castle." Although code varied both among and within groups, it often reflected expertise present at each school that students at the other campus would not have (e.g., a UCLA student would not describe the Figure 1 picture with the name "Millikan," and may not even recognize a bridge over a pond).

In each experimental session, six students at UCLA start out in one group and six students at Caltech are in another group. Each group participated in a 40-round training phase, in which the group would have to name pictures from its own campus, to cement a campus-specific code. Then two people from each school were placed in a "mixed" group, while the remaining four participants at each school stayed in an "unmixed" group. Members of the mixed group saw pictures from both schools, so about half of the pictures each member saw (and the code others used) would be new to her. The formation of this mixed group is like a horizontal merger. Employees from two distinct firms are forced to work together on a common task. Each person can contribute some expertise, but everyone must learn how to communicate with each other, since the code they were previously able to use freely in their own organization may not be understood by others.

Picture-naming of this sort is like a business where one worker has private information about which of many scenarios is occurring and must convey it to another worker who can "see" possible scenarios in the mind's eye. The analogy between the lab and the field holds if one 
accepts the hypothesis that experimental subjects seeing pictures on a screen is like highly-expert employees who have memories of possible scenarios in their minds.

An example is emergency services like police dispatching, where the dispatcher has talked to witnesses to a crime and must translate their natural language into code that tells rapidly-reacting cops what kind of crime scene to expect. Another example is location scouting for a film: The location scout sees a physical location and must convey it to a director who cannot see the scene. Still another is a busy restaurant kitchen. Imagine an American tourist in Japan who strays into a local restaurant, and orders by pointing to pictures on a menu or plastic replicas in a counter case. A waiter then conveys the order to a cook, but the cook cannot see what the tourist pointed to. The cook can visually imagine all the possible dishes; the waiter's job is to use language so that the cook imagines the dish that corresponds to what the tourist pointed to. This task is very much like the picture-naming task, except that the Japanese cook "sees" the pictures in his mind rather than on a computer screen. In a restaurant that is extremely busy, code that is fast and clear is an asset in production.

We use various measures of performance in the picture-naming task as a way to compare mixed, or merged groups, containing two members from each school, to the unmixed groups that contain members from a single school. We reward quick picture identification and penalize mistakes, so earnings serve as a composite measure of productivity. Since the messages are recorded, we can also count the number of characters used to describe each picture. Groups can earn more if their code is short, but there may be limits to how short code can become without hurting employees' ability to accurately identify an image. 


\section{a. Hypotheses}

While subjects in the unmixed groups see pictures they are already familiar with, the merged groups face a more difficult task. About half the pictures a member of the merged group sees will be from the other school, and members of this group are expected to have trouble communicating with each other. We anticipate that merged groups will not perform as well as the other groups, unless the members are able to gain enough experience to develop efficient code. However, since merged groups only participate in a small number of rounds in the picturenaming task, they are unlikely to gain sufficient experience. Even though members of merged groups will be paid an additional sum of money, we do not think it will compensate for the greater difficulty the merged groups face. This leads to an obvious first hypothesis:

H1: Subjects in the mixed group will earn less than subjects in the unmixed group, even when their additional payments are counted as part of their earnings.

If performance is worse in the mixed group, it is interesting to know whether subjects can correctly anticipate the difficulty the merged group will have. Expectations of post-merger performance are measured in two ways. First, we ask subjects to record their guesses about the average amount a member of a merged group will earn during the picture-naming task. We can later compare this number to the actual average earnings of the merged group members. Second, subjects place bids which are the additional amount of money they would need to be paid to join the mixed (merged) group. The subjects who ask for the lowest additional payments are placed in the merged group.

If subjects fail to account for the difficulty of the picture naming in the mixed group, guesses of average earnings will be higher than the actual earnings, and bids will be too low. These overvaluations would be akin to a situation in which two firms guess that a merger will be 
easy and it is actually harder than they expect. In our design, participants may underestimate the difficulty of the merger because of a judgment bias, the "curse of knowledge," in which people act as if their expertise and knowledge is more widely-shared than it is (Camerer, Loewenstein, and Weber, 1989). People have also shown a tendency to assume that their strong emotions and deceptions are more transparent to others than they really are (Gilovich, Medvec, and Savitsky, 1998). An illustration of this judgmental bias comes from a simple experiment (cited in Griffin and Ross, 1991), in which participants would tap out a well-known song on a table and estimate the proportion of listeners that would correctly identify the tune. Subjects had trouble realizing how difficult it would be for the listeners to interpret a succession of knocks on a table as the rich melody the subjects could "hear" inside their heads, causing them to overestimate the number of correct guesses.

In our study, participants in the merged group who see a picture from their own campus will generally be inclined to describe it with its proper name or with the short code that had previously been used for that picture. People from the other school should not be expected to know the proper names, but participants may believe that short descriptions will be quickly understood. For example, when a manager from UCLA is looking at a picture of Kerckhoff Hall, which he tries to describe as "brick building," he may fail to realize that the other participants are looking at a series of pictures that contain 3 different brick buildings. The curse of knowledge, combined with the scramble to create new code, can cause difficulties for group members at the manager's school as well as at the other school.

These ideas lead to a second hypothesis:

$\mathrm{H} 2$ : Subjects will overvalue the merger, guessing average earnings for the mixed group that are higher than the actual earnings of that group. 
The alternative hypothesis to $\mathrm{H} 2$ is rationality of expectations: guesses and bids correctly anticipate, in the sense of a zero mean forecast error, the earnings differential between groups.

\section{Design Details}

Nine sessions were run between April and May of 2004. Another four sessions, which differed from the original nine in the bidding phase, were run between October and December of 2004. ${ }^{2}$ Each session was conducted simultaneously at UCLA and Caltech. All instructions were the same for both schools. Subjects were UCLA and Caltech undergraduate and graduate students. $^{3}$

The experiment contains three phases, though each phase is composed of a few distinct tasks (Figure 3). One of these tasks is the picture-naming task, in which subjects describe and identify pictures that they see on their computer screens. ${ }^{4}$ The basic structure of this task is the same in each phase. In every round, each person in a group sees eight pictures on her computer screen, which are chosen randomly from a larger set of 16 pictures. Pictures are displayed in a random order on each person's screen. One person is designated as the "manager." On the manager's screen, four of the pictures are numbered 1 to 4 . The manager must describe these four pictures to the "employees" by typing messages that are sent to all members of the group. The employees click on a picture to identify it. Once each employee has correctly identified the four pictures, or if time runs out (after 300 seconds), the next round begins. The manager rotates

\footnotetext{
${ }^{2}$ A fifth session is excluded from the analysis because one subject with a visual disability insisted on participating but was very poor at the picture-naming task, which caused the entire group to perform very poorly.

${ }^{3}$ One person at UCLA participated twice (a filtering error) but all others participated only once. The results do not change substantially if we exclude this person's groups from the analysis. ${ }^{4}$ The experiments used CultureX software, developed by Charlie Hornberger and John Lin. Documentation on this software is available at http://ruffian.caltech.edu/cx-docs/ .
} 
cyclically in each round, so participant 1 is the manager in the first round, 2 is the manager in the second round, and so on. ${ }^{5}$

Payments for this task are a function of time and accuracy. Employees earn $\$ 0.60$ each round, minus $\$ 0.005$ for every second it takes to complete the task, and minus $\$ 0.50$ for each incorrect guess. Managers earn the average of the employees' payoffs. This payment structure rewards good code. The better participants are at creating short but clear descriptions of each picture, the better they will perform.

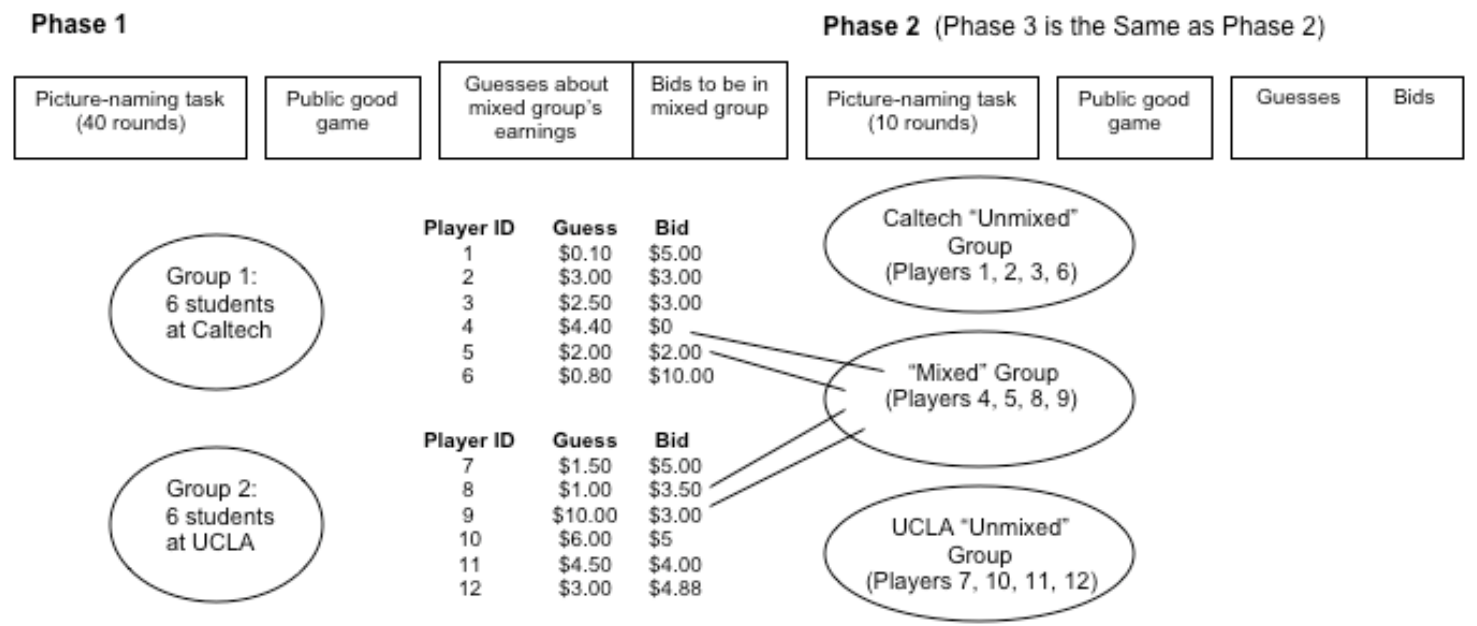

Figure 3. Timeline of tasks in experiment.

Figure 3 is a diagram of the events that occur in each phase of the experiment. The first familiarizes subjects with the picture naming task and allows them to create code in their "area (campus) of expertise." Before this phase begins, participants receive a brief set of instructions,

\footnotetext{
${ }^{5}$ Our primary reason for choosing to rotate the manager is based on the finding of Weber, Rick, and Camerer (2004) that groups with rotating managers incorporate new employees better than do groups with a fixed manager. Using a rotating manager biases the results against the hypothesis that subjects will underestimate the difficulty of the merger. Rotation also prevents outliers that can occur with a single fixed manager who is unusually good or bad.
} 
and then they participate in a short four-period practice session with different pictures. Subjects also complete a short quiz to ensure that they understand the task.

As mentioned earlier, in the first phase there are two separate groups-six UCLA students in one group, and six Caltech students in the other group. Each group sees subsets of 16 pictures from their own campus. There are 40 rounds of the picture-naming task in this stage. Following this stage, subjects take part in a public good game. ${ }^{6}$

The second phase is the first merger phase. At the beginning of this phase, subjects are told that they will participate in the picture naming task for 10 more periods, but instead of being in two groups of six, they will be divided into three groups of four. We explain that of the six people at each school, two will be chosen to be in a "mixed" group. The mixed group will see eight pictures at a time, randomly drawn from a set containing pictures from both original groups, so on average half the pictures each person sees will be new to her. However, in addition to the normal earnings, she will be paid an additional amount to join the mixed group. The four people at each school who are not in the mixed group will do exactly the same task as they did in the first phase, except in a four-person group rather than a six-person group. ${ }^{7}$

\footnotetext{
${ }^{6}$ The game was a binary public good game in which subjects could keep $\$ 1$ or contribute $\$ 2$ to the group, which was shared equally, in the first-price sessions only. The game was designed to test whether suffering through a merger would reduce group camaraderie in a way that is behaviorally expressed by lower cooperativeness. Across sessions, $73 \%$ contributed after the first 40 rounds. After the first two merger phases, the contribution rates were $56 \%$ and $39 \%$ for unmixed groups, and 50\% and 56\% for mixed groups. Comparing average contributions using group-level analyses yields no significant differences $\left(\mathrm{t}_{25}=0.473, \mathrm{p}=0.320\right.$ for the first phase and $t_{25}=-1.543, p=0.068$ for the second phase). Because there are no interesting effects, we say nothing about this game in the text below. It is possible that there is simply no effect of code creation on "camaraderie", or that the earnings shortfall of mixed group members actually created more camaraderie (perhaps from suffering through a difficult bonding experience) rather than less, or that the two effects are simply too weak to find in this experiment.

${ }^{7}$ We call this group "same" in the experimental instructions.
} 
After explaining the basic structure of the merger, subjects are asked to guess how much the average person in the mixed group will earn over the next 10 periods (excluding the additional payments from bids). They are reminded of the average earnings in each group in the original picture-naming task, over all 40 periods and also over the last 10 periods, to help subjects use these data in making their estimates. They also see sample pictures from the twocampus pool the mixed group will see. Subjects who are not in the mixed group are paid $\$ 2.00$ if they guess an amount within $\$ 0.50$ of the actual average earnings of the mixed group. ${ }^{8}$

When subjects have written down their guesses, they are given instructions on the merger bidding process. Subjects are asked to write down the additional amount they would need to be paid to join the mixed group. They write this as a total for the ten periods. The two people from each original group who bid the lowest amounts are the ones who are placed in the mixed group. ${ }^{9}$ Then the mixed group and two unmixed groups participate in 10 rounds of the picture-naming task. Members of the unmixed group at each school again see pictures from their own campus, while members of the mixed group see pictures from a set containing eight UCLA campus pictures and eight Caltech campus pictures. The eight pictures from each campus were selected randomly from each original set of 16. Members of the mixed group earn money from their performance in the picture-naming task plus the amount they bid to join the group.

The second merger stage (or third phase of the experiment) is run exactly like the preceding phase, with two exceptions. The first is that before making their guesses, subjects are

\footnotetext{
${ }^{8}$ If subjects in the mixed group were also paid for accurate guesses, they would have an incentive to guess very low amounts and then perform poorly; this method of payment is incentive-compatible.

${ }^{9}$ To be sure they understood the auction procedure, participants first write down a practice bid. The experimenter collects these bids, then announces which two people would be in the mixed group if the bids were counted, though she does not announce their bids. The bidding forms are then handed back, so subjects can revise their initial bid if they wish.
} 
told the average earnings of the mixed group in the prior ten-period picture-naming task. The other difference is that people may leave or enter the mixed group in this stage, based on their bids. At the end of the second merger stage, each subject is paid according to his or her total earnings from all parts of the experiment.

The last four sessions used a different auction mechanism than the first nine sessions. ${ }^{10}$ The primary difference lay in the style of auction conducted to place members in the mixed group. While the first-price auction we used in the first nine sessions is easy to explain to subjects, in theory, subjects will bid more than their valuations. To try to make subjects ask for their lowest acceptable payment, we conducted the last four sessions with a Vickrey, or secondprice, auction. As before, the two subjects from each school who bid the lowest amounts joined the mixed group, but in these sessions, they were all paid the third-lowest bid. The experimental instructions explained why the auction is incentive-compatible: Subjects should bid exactly the minimum amount they would accept, because their bid does not determine the amount they actually get paid.

\section{Results}

\section{a. Auction Treatments}

We first compare data from the first-price and Vickrey sessions. Bids do differ between the two treatments, as predicted by theory. In the first merger stage, Vickrey bids are significantly lower than first-price bids (Kolmogorov-Smirnov test, $\mathrm{p}=0.007$ ). ${ }^{11}$ In the second merger stage, there is no significant difference between bids across the two treatments (K-S test,

\footnotetext{
${ }^{10}$ The other difference in the last four sessions was that the public good game was not conducted at all.

${ }^{11}$ Since some bids are very large, a non-parametric test is used to compare bidding behavior, rather than determining an arbitrary cut-off point to exclude outliers. The K-S test will also be used for other bid comparisons in the paper.
} 
$\mathrm{p}=0.877)$. As we will see later, bids in the first-price sessions remained stable across the two merger stages, but those in the Vickrey treatment rose significantly between the two stages.

Keep in mind that in first-price low-bid auctions of this type, with six bidders competing for two "objects," equilibrium bidding requires subjects to bid more than their reservation price (trading off the risk of losing the auction for additional surplus), just as in high-bid auctions, bidders should underbid. Most experiments do show strategic bidding of this sort (e.g., Kagel, 1995). Extrapolating from these earlier experiments (and theory), it is likely that first-price bids are inflated relative to true reservation prices. ${ }^{12}$ The gap between the median Vickrey-auction bid ( $\$ .30$ in merger phase I) and the median first-price auction bid ( $\$ .50$ in merger phase I) is consistent with strategic inflation of bids in the first-price auctions.

The Vickrey treatment was added because, in theory, subjects should just bid their guess about the earnings differential-- i.e., bidding one's valuation is a dominant strategy, so there is no strategic incentive to inflate bids. ${ }^{13}$ The fact that bids are lower in the Vickrey auctions than in the first-price auctions suggests that switching auction mechanisms reduces the extent of strategic inflation, which makes the Vickrey data, in theory, a better test of whether participants are underestimating the difficulty of the mergers. We also used an alternative econometric

\footnotetext{
${ }^{12}$ Bids and guesses are uncorrelated in the first merger phase for both treatments (Spearman $\mathrm{r}=-$ $0.10, p=0.29$ and $r=-0.01, p=0.96$ for first-price and Vickrey, respectively). This suggests that differences in bid strategy across subjects are present and account for some of the variation between bids and guesses. In the second merger phase, the guesses (about mixed-group total earnings) and bids (amounts demanded to join the mixed group, which presumably reflect expected earnings differences) have reasonable negative correlations, as expected $(\mathrm{r}=-0.50$, $\mathrm{p}<0.001, \mathrm{r}=-0.44, \mathrm{p}=0.002)$.

${ }^{13}$ In experiments, subjects sometimes inflate bids strategically even in Vickrey auctions, where there is no incentive to do so. Kagel (1995) reviews studies in which subjects do not bid their values in second-price auctions. Grether et al (2004) provide neural evidence on the difficulty people have in finding the dominant strategy in these auctions.
} 
procedure to infer unobserved valuations from actual first-price bids (assuming that subjects are making equilibrium bids; Guerre, Perrigne, and Vuong, 2000).

\section{b. Overall Performance}

Tables $1 \mathrm{a}$ and $1 \mathrm{~b}$ give average (per-period) statistics for performance, guesses, and bids.

Figure 4 shows average earnings across sessions, before additional payments for the mixed group are included. The earnings for Caltech and UCLA students are pooled. ${ }^{14}$

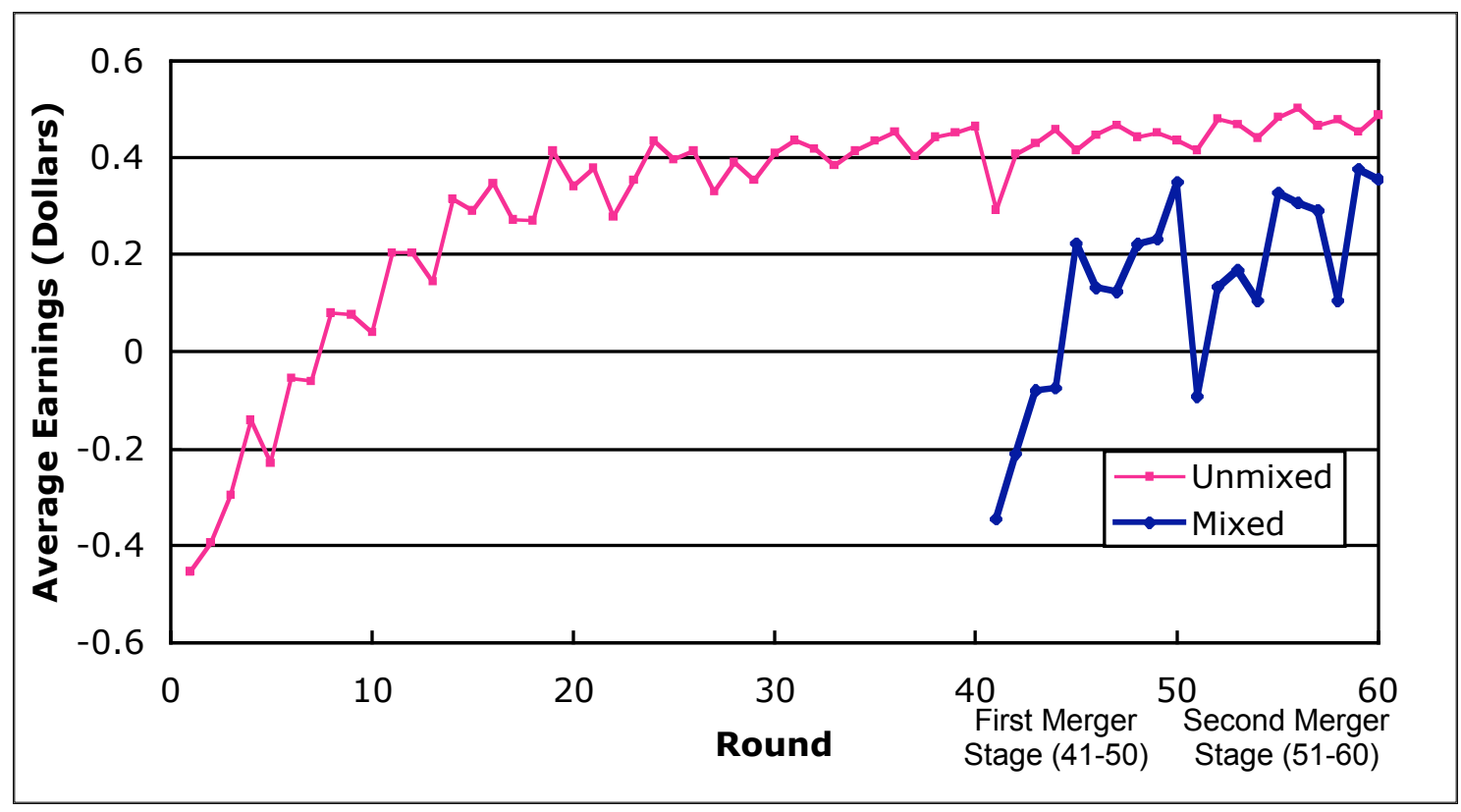

Figure 4. Average earnings across rounds, all phases.

During the initial 40 rounds, earnings grew as subjects became faster at identifying pictures and made fewer mistakes. (See Appendix 1 for average completion times and mistakes by round.) From round to round, there is a great deal of variability in subjects' earnings. Often a

\footnotetext{
${ }^{14}$ Although Caltech students earned significantly more than UCLA students, no interaction was found between being a Caltech student and being in the mixed group. Since the differences between mixed and unmixed groups do not vary by school, we pool data here for ease of exposition.
} 


\begin{tabular}{|c|c|c|c|c|c|c|c|}
\hline & Group & $\begin{array}{l}\text { Average } \\
\text { Earnings } \\
\text { (Dollars) }\end{array}$ & $\begin{array}{c}\text { Average } \\
\text { Number } \\
\text { of } \\
\text { Mistakes }\end{array}$ & $\begin{array}{c}\text { Average } \\
\text { Completion } \\
\text { Time } \\
\text { (Seconds) }\end{array}$ & $\begin{array}{c}\text { Median } \\
\text { Guesses } \\
(\$)\end{array}$ & $\begin{array}{l}\text { Median } \\
\text { Bids* } \\
(\$)\end{array}$ & $\begin{array}{c}\text { Median } \\
\text { inferred } \\
\text { value }(\$) \\
* *\end{array}$ \\
\hline $\begin{array}{l}\text { Rounds } \\
1-40\end{array}$ & $\begin{array}{l}\text { All } \\
(n=108)\end{array}$ & $\begin{array}{l}0.246 \\
(0.475)\end{array}$ & $\begin{array}{l}0.29 \\
(0.79)\end{array}$ & $\begin{array}{l}42.1 \\
(32.6)\end{array}$ & & & \\
\hline \multirow[t]{3}{*}{$\begin{array}{l}\text { Merger } \\
\text { phase } 1 \\
\end{array}$} & $\begin{array}{l}\text { Unmixed } \\
(\mathrm{n}=72)\end{array}$ & $\begin{array}{l}0.421 \\
(0.206)\end{array}$ & $\begin{array}{l}0.13 \\
(0.38)\end{array}$ & $\begin{array}{l}22.7 \\
(11.1)\end{array}$ & $\begin{array}{l}0.313 \\
(0.249)\end{array}$ & $\begin{array}{l}0.600 \\
(0.482)\end{array}$ & $\begin{array}{l}0.490 \\
(0.495)\end{array}$ \\
\hline & $\begin{array}{l}\text { Mixed } \\
(n=36)\end{array}$ & $\begin{array}{l}0.106 \\
(0.468) \\
\end{array}$ & $\begin{array}{l}0.40 \\
(0.86) \\
\end{array}$ & $\begin{array}{l}58.0 \\
(30.5) \\
\end{array}$ & $\begin{array}{l}0.288 \\
(0.171) \\
\end{array}$ & $\begin{array}{l}0.300 \\
(0.169) \\
\end{array}$ & $\begin{array}{l}0.025 \\
(0.191) \\
\end{array}$ \\
\hline & & & & & $\begin{array}{l}\text { All: } 0.300 \\
(0.225)\end{array}$ & $\begin{array}{l}\text { All: } 0.500 \\
(0.461)\end{array}$ & $\begin{array}{l}\text { All: } 0.381 \\
(0.397)\end{array}$ \\
\hline \multirow[t]{3}{*}{$\begin{array}{l}\text { Merger } \\
\text { phase } 2 \\
\end{array}$} & $\begin{array}{l}\text { Unmixed } \\
(\mathrm{n}=72)\end{array}$ & $\begin{array}{l}0.470 \\
(0.130) \\
\end{array}$ & $\begin{array}{l}0.06 \\
(0.24) \\
\end{array}$ & $\begin{array}{l}19.7 \\
(7.6) \\
\end{array}$ & $\begin{array}{l}0.138 \\
(0.139) \\
\end{array}$ & $\begin{array}{l}0.525 \\
(0.347) \\
\end{array}$ & $\begin{array}{l}0.445 \\
(0.401) \\
\end{array}$ \\
\hline & $\begin{array}{l}\text { Mixed } \\
(\mathrm{n}=36)\end{array}$ & $\begin{array}{l}0.246 \\
(0.339)\end{array}$ & $\begin{array}{l}0.24 \\
(0.66)\end{array}$ & $\begin{array}{l}48.6 \\
(24.8)\end{array}$ & $\begin{array}{l}0.150 \\
(0.158)\end{array}$ & $\begin{array}{l}0.315 \\
(0.183)\end{array}$ & $\begin{array}{l}0.045 \\
(0.205)\end{array}$ \\
\hline & & & & & $\begin{array}{l}\text { All: } 0.150 \\
(0.145)\end{array}$ & $\begin{array}{l}\text { All: } 0.500 \\
(0.342)\end{array}$ & $\begin{array}{l}\text { All: } 0.415 \\
(0.310)\end{array}$ \\
\hline
\end{tabular}

Table 1a. Summary statistics for first-price sessions, per period.

\begin{tabular}{|c|c|c|c|c|c|c|}
\hline & Group & $\begin{array}{c}\text { Average } \\
\text { Earnings } \\
\text { (Dollars) }\end{array}$ & $\begin{array}{c}\text { Average } \\
\text { Number of } \\
\text { Mistakes }\end{array}$ & $\begin{array}{c}\text { Average } \\
\text { Completion } \\
\text { Time } \\
\text { (Seconds) }\end{array}$ & $\begin{array}{c}\text { Median } \\
\text { Guesses } \\
\text { (Dollars) }\end{array}$ & $\begin{array}{c}\text { Median } \\
\text { Bids* } \\
\text { (Dollars) }\end{array}$ \\
\hline $\begin{array}{l}\text { Rounds } \\
1-40\end{array}$ & $\begin{array}{l}\text { All } \\
(n=48)\end{array}$ & $\begin{array}{l}0.210 \\
(0.161)\end{array}$ & $\begin{array}{l}0.29 \\
(0.22)\end{array}$ & $\begin{array}{l}43.3 \\
(12.3)\end{array}$ & & \\
\hline \multirow[t]{4}{*}{$\begin{array}{l}\text { Merger } \\
\text { phase } 1\end{array}$} & $\begin{array}{l}\text { Unmixed } \\
(\mathrm{n}=32)\end{array}$ & $\begin{array}{l}0.432 \\
(0.049)\end{array}$ & $\begin{array}{l}0.07 \\
(0.09)\end{array}$ & $\begin{array}{l}23.5 \\
(4.0)\end{array}$ & $\begin{array}{l}0.258 \\
(0.243)\end{array}$ & $\begin{array}{l}0.480 \\
(1.016)\end{array}$ \\
\hline & $\begin{array}{l}\text { Mixed } \\
(n=16)\end{array}$ & $\begin{array}{l}-0.052 \\
(0.294)\end{array}$ & $\begin{array}{l}0.56 \\
(0.45) \\
\end{array}$ & $\begin{array}{l}54.9 \\
(11.3) \\
\end{array}$ & $\begin{array}{l}0.355 \\
(0.166)\end{array}$ & $\begin{array}{l}0.138 \\
(0.122)\end{array}$ \\
\hline & $\begin{array}{l}\text { Third- } \\
\text { lowest } \\
(\mathrm{n}=8)\end{array}$ & & & & & $\begin{array}{l}0.313 \\
(0.162)\end{array}$ \\
\hline & & & & & $\begin{array}{l}\text { All: } 0.291 \\
(0.219)\end{array}$ & $\begin{array}{l}\text { All: } 0.350 \\
(0.902)\end{array}$ \\
\hline \multirow[t]{4}{*}{$\begin{array}{l}\text { Merger } \\
\text { phase } 2 \\
\end{array}$} & $\begin{array}{l}\text { Unmixed } \\
(\mathrm{n}=32)\end{array}$ & $\begin{array}{l}0.463 \\
(0.036)\end{array}$ & $\begin{array}{l}0.04 \\
(0.06)\end{array}$ & $\begin{array}{l}21.2 \\
(3.6)\end{array}$ & $\begin{array}{l}0.150 \\
(0.203)\end{array}$ & $\begin{array}{l}0.575 \\
(0.576)\end{array}$ \\
\hline & $\begin{array}{l}\text { Mixed } \\
(n=16)\end{array}$ & $\begin{array}{l}0.120 \\
(0.206)\end{array}$ & $\begin{array}{l}0.37 \\
(0.27)\end{array}$ & $\begin{array}{l}46.4 \\
(7.7)\end{array}$ & $\begin{array}{l}0.108 \\
(0.177)\end{array}$ & $\begin{array}{l}0.300 \\
(0.224)\end{array}$ \\
\hline & $\begin{array}{l}\text { Third- } \\
\text { lowest } \\
(n=8)\end{array}$ & & & & & $\begin{array}{l}0.448 \\
(0.228)\end{array}$ \\
\hline & & & & & $\begin{array}{l}\text { All: } 0.135 \\
(0.194)\end{array}$ & $\begin{array}{l}\text { All: } 0.500 \\
(0.524)\end{array}$ \\
\hline
\end{tabular}

Table 1b. Summary statistics for Vickrey sessions, per period.

* Outlying bids above the $97^{\text {th }}$ percentile are set to the highest bid below the $97^{\text {th }}$ percentile for the purpose of computing standard deviations. **Only values between 0 and 20 are used for computing standard deviations. 
large dip in earnings was caused by a manager who did not use the established code for a picture or who confused employees by describing several pictures at once. The random draws of pictures each period could also make the task more or less difficult in a given round, since some images are fairly similar and others are distinct. ${ }^{15}$ Despite variance in Figure 4, a trend is readily apparent. Earnings increased over time for the unmixed groups, eventually asymptoting at around $\$ 0.45$ per round. The mixed groups also increased performance over time, nearly reaching the earnings of the unmixed groups by the end of the two merger phases of 20 total rounds.

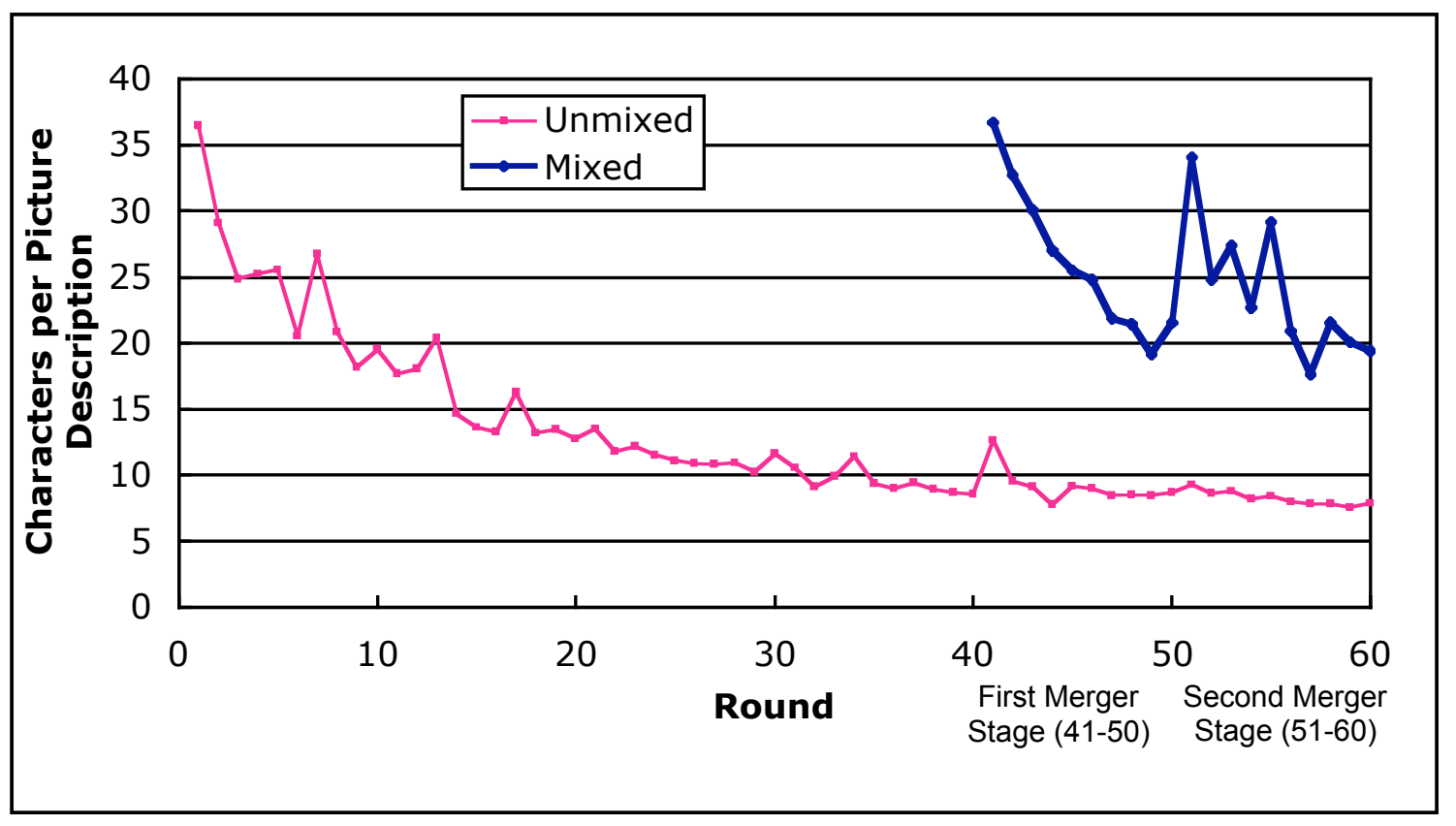

Figure 5. Average code length (characters per picture) by round. ${ }^{16}$

\footnotetext{
${ }^{15}$ Software problems could also cause low earnings. For each of the eight rounds in which we were aware that a software glitch occurred, we interpolated data on earnings, completion time, and incorrect guesses from the two surrounding rounds.

${ }^{16}$ One outlier was excluded from the analysis. In the first round of the second merger stage, one manager of a mixed group typed advice to the employees before starting to describe the pictures, causing that group to have a large number of characters per picture. With the outlier included, the average for the mixed group in round 51 is 49.9 ; without the outlier, it is 34.1 .
} 
Figure 5 depicts average code length (the number of characters used by the manager to describe a single picture) across rounds. There are a few interesting features of Figure 5. The first to note is the relationship between increasing earnings and decreasing code length (that is, Figure 5 looks like an inverse of Figure 4). Groups completed each round quickly once they had established clear, short codes for each picture. Another feature is the similarity of the decrease in code length for the first mixed group in rounds 41-50 and the original groups in early rounds 110. The mixed group initially used slightly longer descriptions than the original groups at each school had, but both the mixed and the original groups reduced their code to about 20 characters

per description by the end of 10 rounds. One would expect the mixed group to take a longer time to shorten the code than the original groups, since the original groups could easily use names of buildings and other campus features in their descriptions. This result may reflect subjects' improved ability to create new code after 40 training periods, or the fact that subjects in many mixed groups tried to teach each other the code they had previously used for each picture in the training stage.

\section{c. First Merger Stage}

The mixed groups clearly have more trouble with the picture-naming task than the unmixed groups. They use longer code, take more time, and make more costly mistakes. The next question is whether subjects accurately anticipate the worse performance of the mixed groups. The evidence indicates subjects are generally too optimistic, but the results are somewhat sensitive to the type of bids.

There are three ways to measure whether subjects correctly forecasted the lower earnings in the mixed group - guesses, bids, and (for the first-price auctions) inferred values. Table 2 summarizes the differences between these statistics and the actual mixed-group earnings. 
Guesses in the first merger phase were generally too optimistic. Eighty-four percent of the forecast errors (actual earnings minus guesses) were negative, and 69 percent of the guesses were more than $\$ 1$ above the mixed group's actual earnings.

\begin{tabular}{|c|c|c|c|c|}
\hline \multicolumn{2}{|c|}{} & $\begin{array}{c}\text { Mean forecast } \\
\text { error (std. } \\
\text { error) }\end{array}$ & $\begin{array}{c}\text { Mean net } \\
\text { earnings } \\
\text { differential (std. } \\
\text { error) }\end{array}$ & $\begin{array}{c}\text { Mean inferred net } \\
\text { earnings } \\
\text { differential (std. } \\
\text { error) }\end{array}$ \\
\hline $\begin{array}{c}\text { Merger } \\
\text { phase }\end{array}$ & $\begin{array}{c}\text { Auction } \\
\text { type }\end{array}$ & $\begin{array}{c}\text { Mixed earnings- } \\
\text { guesses }\end{array}$ & $\begin{array}{c}\text { (Bid + mixed } \\
\text { earnings) - } \\
\text { unmixed earnings }\end{array}$ & $\begin{array}{c}\text { (Inferred value* + } \\
\text { mixed earnings) - } \\
\text { unmixed earnings }\end{array}$ \\
\hline 1 & $1^{\text {st }}$ price & $-0.194(0.024)$ & $0.024(0.024)$ & $-0.147(0.263)$ \\
\hline 1 & Vickrey & $-0.343(0.053)$ & $-0.315(0.054)$ & \\
\hline 2 & $1^{\text {st }}$ price & $0.096(0.013)$ & $0.117(0.021)$ & $-0.036(0.234)$ \\
\hline 2 & Vickrey & $-0.015(0.019)$ & $0.036(0.012)$ & \\
\hline
\end{tabular}

Table 2. Summary of per-period average forecast errors and earnings differentials. Errors should be negative if subjects are too optimistic, and positive if they are too pessimistic.

*Negative values are set to 0 .

Because forecast errors are correlated (due to shared dependence on the mixed-group average earnings), we use a random resampling bootstrapping method to estimate a confidence interval around the mean forecast error. Pooling both auction conditions, the mean error is $\$ 2.42$ (for all 10 periods), with a $95 \%$ confidence interval of $[-2.85,-1.99]$, so the difference between the forecast errors and zero is highly significant.

Analysis of bids is a bit less conclusive, but it is suggestive that bidders who join the mixed group underestimate the earnings differential. One test focuses on mixed-group earnings with bids added in, minus unmixed-group earnings. If this difference is negative then subjects 
who make low bids and join the mixed group earn less than their counterparts in the unmixed group.

First note that there are three possible levels of analysis - taking each session as a data point, taking each group as a data point, and taking each subject as a data point. Since each subject shares a common group experience, their earnings differentials are correlated so traditional tests assuming independence will overstate significance. Taking each session as a data point creates a small sample and is the most conservative test. We will generally compromise and report the group-level analysis, noting the least conservative individual analysis and the most conservative session analysis in footnotes. In both auction sessions, there is a clear difference between earnings of unmixed groups and mixed groups before bids are added in, as expected, which is highly significant at all levels of analysis. ${ }^{17}$

The crucial comparison is between mixed-group earnings with bids added in (i.e., the amount the mixed-group subjects actually earned), and unmixed-group earnings. The results differ across the two auction treatments. In the Vickrey treatment the mixed-plus-bid earnings average $\$ 1.17$, and unmixed groups average $\$ 4.32$. The difference is significantly negative for groups $\left(\mathrm{t}_{10}=2.344, \mathrm{p}=0.021\right) .{ }^{18}$ In the first-price treatment the mixed-plus-bid earnings average

\footnotetext{
${ }^{17}$ The results with individuals as the unit of analysis are $\mathrm{t}_{106}=13.208, \mathrm{p}<.001$ in first-price treatment, and $\mathrm{t}_{46}=9.166, \mathrm{p}<.001$ in Vickrey. The results with groups as the unit of analysis are $\mathrm{t}_{25}=8.100, \mathrm{p}<.001$ in first-price and $\mathrm{t}_{10}=4.680, \mathrm{p}<.001$ in Vickrey sessions. The results with session-level analysis are $\mathrm{t}_{8}=5.780, \mathrm{p}<.001$ in first-price treatment and $\mathrm{t}_{3}=3.304, \mathrm{p}=0.023$ in Vickrey treatment.

${ }^{18}$ In the Vickrey sessions, a subject in the mixed group would earn an additional amount greater than or equal to her bid, but her bid reflects her valuation of the merger, so the sum of performance-based earnings and bids is the proper measure to use here. The individual analysis result is $\mathrm{t}_{46}=4.623, \mathrm{p}<.001$; the session analysis result is $\mathrm{t}_{3}=1.632, \mathrm{p}=0.101$ for the one-tailed, one-sample test.
} 
$\$ 4.45$, and unmixed groups average $\$ 4.21$. This small difference is not significant in the grouplevel analysis $\left(\mathrm{t}_{25}=0.528, \mathrm{p}=0.301\right)$ or at any other level. ${ }^{19}$

However, keep in mind that bids in the first-price treatment are, in theory, strategically inflated. Therefore, even if bidders underestimate the difficulty of merging, they could still show a result in which net earnings for mixed groups (with bids added in) and unmixed groups are close together. We use an econometric procedure to estimate underlying valuations from firstprice bids (see Guerre, Perrigne, and Vuong (2000) and Appendix 2). This procedure basically runs a bidding function (which maps values into bids) in reverse: By assuming independent private values and equilibrium bidding, unobserved values can be guessed from bids. Through estimates of the distribution of bids across all sessions, this technique allows us to generate an estimated value for each bidder. This value should be interpreted as the bidder's guess about the expected cost of joining the mixed group. While the estimated value distribution on the whole looked reasonable, the lowest bidders had some fairly large negative inferred values, which are probably an unreasonable artifact of the specification underlying the procedure and hence were excluded..$^{20}$

The only other experimental application of the procedure (Bajari and Hortacsu, 2005) used data in which valuations were known because they were controlled by the experimenter. Their application pretends the values are not known, infers them econometrically, and compares the inferred values to the actual ones under various models of bidding. For values uniformly

\footnotetext{
${ }^{19}$ The individual analysis gives $\mathrm{t}_{106}=0.806, \mathrm{p}=0.211$ and the session analysis gives $\mathrm{t}_{8}=0.360, \mathrm{p}$ $=0.364$ for the one-sample, one-tailed test.

${ }^{20}$ A negative inferred value implies that a bidder would pay a substantial sum to be in the mixed group. This is very likely an artifact of the specification of underlying values in the procedure, because no one in the Vickrey sessions bid a negative amount. We excluded negative values when finding the cumulative distribution of inferred values.
} 
distributed in the interval $[0, \$ 30]$, the average estimation error is only $\$ 1.39$ for a Nash bidding model including risk-aversion, so the procedure shows some promise in the simplest cases.

The value-inference procedure can be used to answer two questions.

First, are inferred underlying values from first-price bids closer to the Vickrey bids than the first-price bids are? If the subjects randomly sampled into the first-price and Vickrey sessions have the same distribution of underlying values (up to sampling error), and the Vickrey subjects are bidding around their values (as they should in theory), then the inferred-value and Vickrey bid distributions should be closer together than the Vickrey and first-price bids are. Figure 6a shows the three cdf's of Vickrey bids, first-price bids, and inferred values, pooling across subjects, for phase I. (The actual cost distribution — that is, the gap between mixed and unmixed earnings - is also plotted as a benchmark.) The value cdf inferred from first-price bids is indeed closer to the Vickrey distribution than the original first-price bids are, though the inferred values are still somewhat higher than the Vickrey bids ( $\mathrm{K}-\mathrm{S}$ test, $\mathrm{p}=0.016)$. This gives some assurance that the value inference procedure is on the right track.

Second, do the Vickrey bids, and first-price inferred values, of subjects who entered the mixed group (those with the lowest bids) approximate the actual costs of merging? Figure $6 \mathrm{~b}$ shows a distribution of the lowest two values for six draws from the inferred-value distribution and Vickrey distribution. We are interested in these artificial distributions because even if the mean inferred valuation is approximately correct (as it appears to be from Figure 6a), if the two lowest bidders' valuations are too optimistic, then they will join mixed groups and be surprised at their poor relative performance. Figure $6 \mathrm{~b}$ shows that there does appear to be such a winner's curse: The low-value distributions (inferred from first-price bids, and using raw Vickrey bids) are well below the actual cost distribution. 


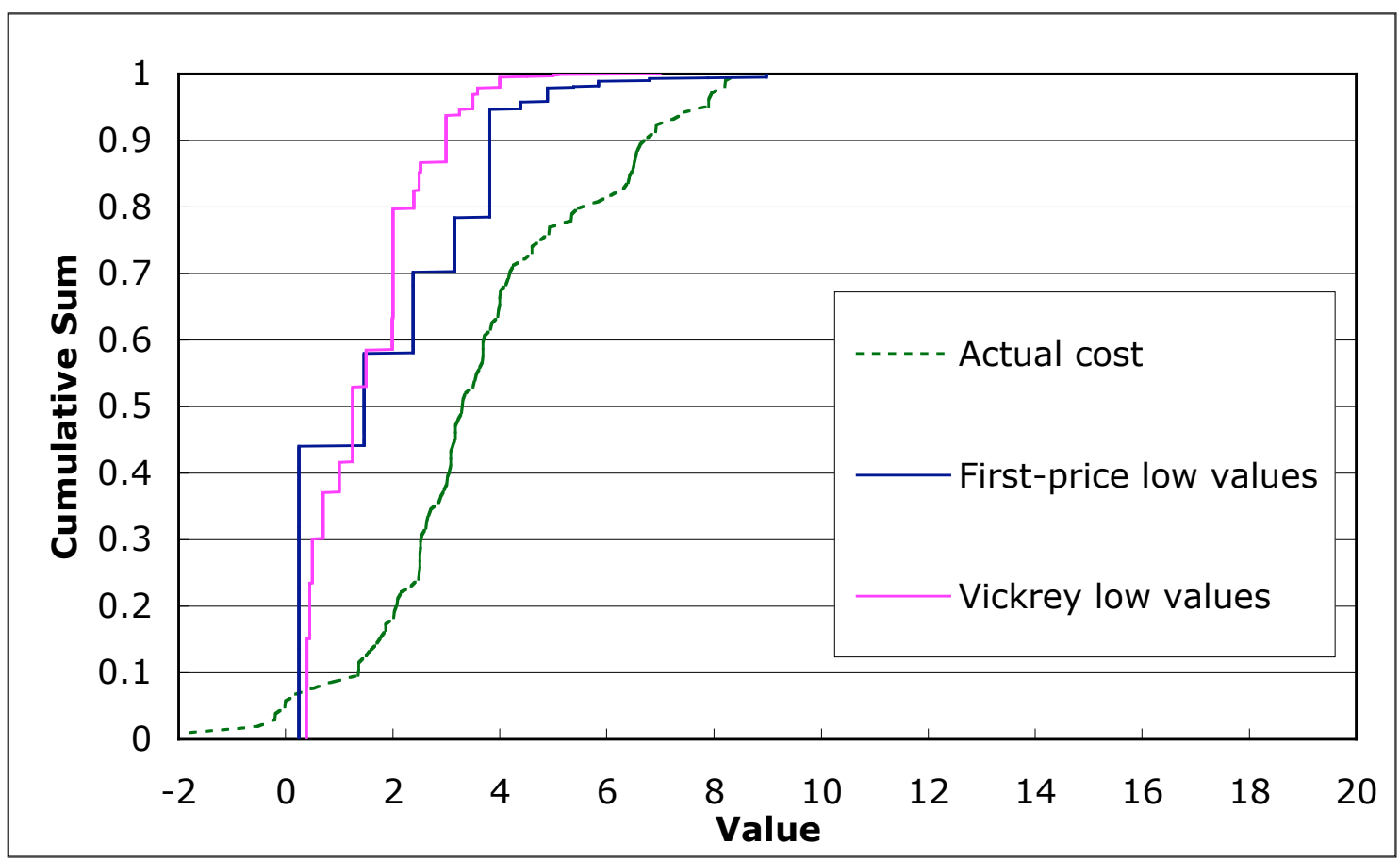

Figure 6a. Bid and inferred value distributions, first merger stage.

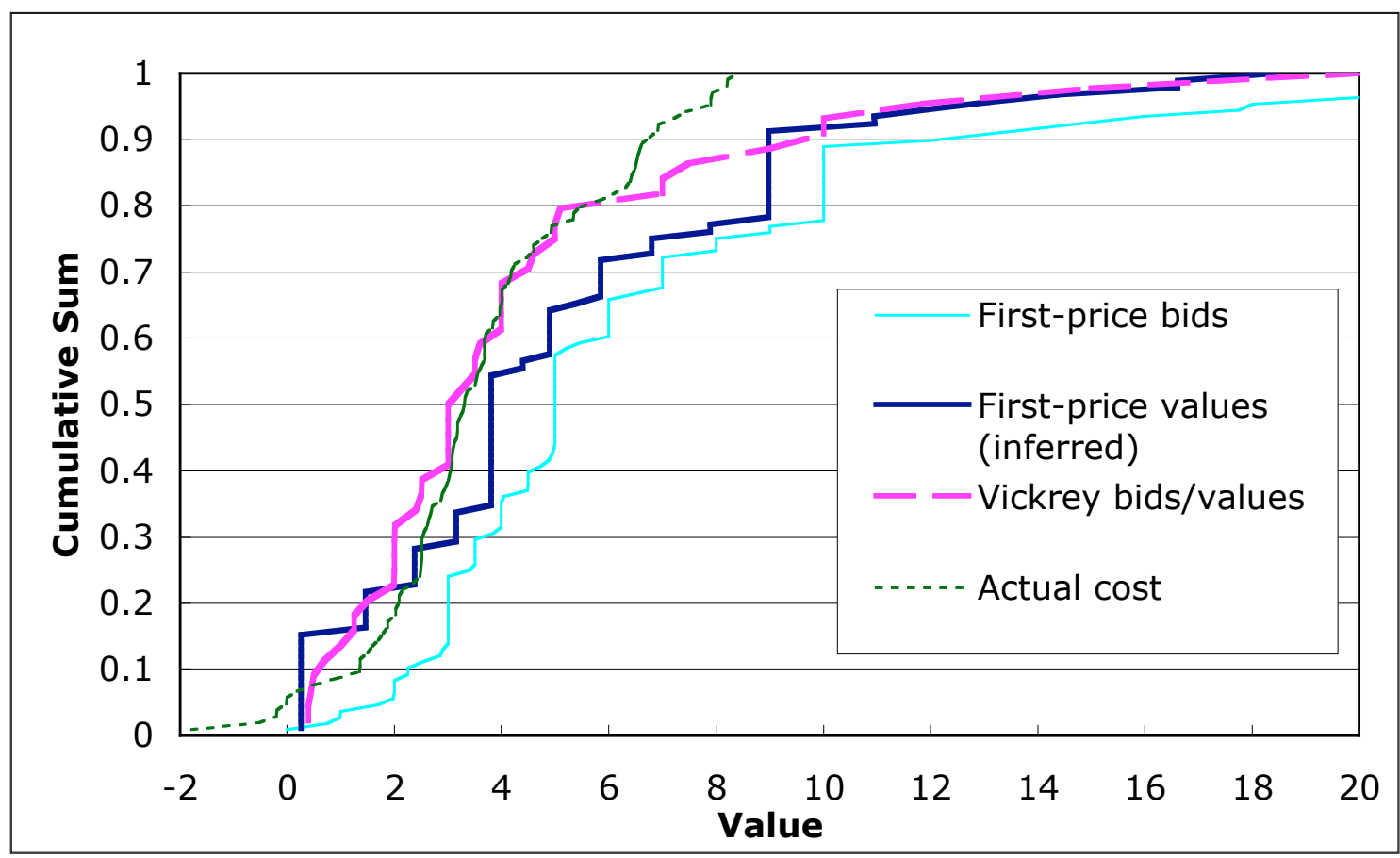

Figure 6b. Distributions of lowest inferred values and Vickrey bids, first merger stage. 
Thus, in the first merger stage, it appears that guesses about mixed-group earnings are generally too optimistic. Furthermore, the average Vickrey bid and the average value inferred from first-price bids are pretty good forecasts of actual costs (the mixed-group minus unmixed earnings difference) but the values of those who joined the mixed group (the low bidders) are too optimistic. It appears that in these simple experiments, subjects have some tendency to be surprised at how difficult assimilation is.

\section{d. Second Merger Stage}

In the second merger stage, guesses and bids are more accurate but are also consistent with anchoring on the results of the first merger stage. Earnings in the second merger phase rise steadily across the 10 periods. By analogy to actual corporate mergers, there appears to be a learning curve in "learning to merge" and create common code rapidly and accurately. The mixed groups suffered an initial dip in earnings compared to the last round of the previous picture-naming task, but within about four periods the mixed groups surpassed the mixed-group performance in the preceding phase and continued to earn more. However, guesses and bids both suggest that subjects did not anticipate this improvement — they are too pessimistic about mixed group performance.

Two thirds of the guesses about mixed-group earnings (67.3\%) were below the average earnings of the mixed group. The mean difference between average earnings and guesses was $\$ .60$, with a $95 \%$ confidence interval of $[\$ .36, \$ .83]$ based on the bootstrap resampling. The fact that $76 \%$ of the guesses were within $\$ 1$ of the mixed-group previous average earnings (which subjects were told) suggests subjects are anchoring on the mixed-group experience in the first stage to forecast the mixed group's experience in the second stage. 
Bids in this stage also indicate anchoring. Bids in the first-price auction treatment were statistically similar in both merger stages. ${ }^{21}$ The average of the winning bids across the two stages is $\$ 3.40$. When bids are added in, the mixed groups in the second merger stage received higher earnings than the unmixed groups $\operatorname{did}\left(\mathrm{t}_{25}=4.16, \mathrm{p}<.001\right.$ for the group analysis). ${ }^{22}$ On average, mixed group members earned $\$ 1.17$ more than members of the unmixed group.

In the Vickrey auction treatment, subjects greatly increased their bids after the first merger stage. ${ }^{23}$ Winning bids rose from an average of $\$ 1.69$ in the first merger phase to $\$ 3.79$ in the second phase. When they are included as part of mixed group members' earnings, these increased bids, as well as an improvement in performance, cause the mixed group members to make significantly more than members of the unmixed groups in the second phase, at the group level $\left(\mathrm{t}_{10}=4.589, \mathrm{p}<.001\right) .{ }^{24}$ Mixed group members earned an average of $\$ .36$ more than the unmixed group members.

The inferred values from the first-price session nearly match the Vickrey values in this second merger stage (K-S test, $\mathrm{p}=0.165$; see Figure $6 \mathrm{c}$ ), so it is not surprising that they are significantly higher than the distribution of actual costs (K-S test, $\mathrm{p}=0.000)$. Figure $6 \mathrm{c}$ highlights the disparity between actual costs in the second merger and the inferred valuations and Vickrey bids. The general overreaction to the previous stage also helped the lowest bidders avoid the

\footnotetext{
${ }^{21}$ The $\mathrm{p}$-value for the combined Kolmogorov-Smirnov test comparing all bids in merger stage one to all bids in merger stage 2 is 0.905 . Comparing only winning bids, $\mathrm{p}=1.000$.

${ }^{22}$ The session result with bids added in is $\mathrm{t}_{8}=2.98, \mathrm{p}=0.009$ and with individuals is $\mathrm{t}_{106}=4.360$, $\mathrm{p}<.001$.

${ }^{23}$ The Kolmogorov-Smirnov test for the hypothesis that stage one bids were lower than stage two bids gives a p-value of 0.030 when all bids are considered, and a p-value of 0.006 when only winning bids are considered.

${ }^{24}$ The session level analysis gives $\mathrm{t}_{3}=1.410, \mathrm{p}=0.127$.
} 


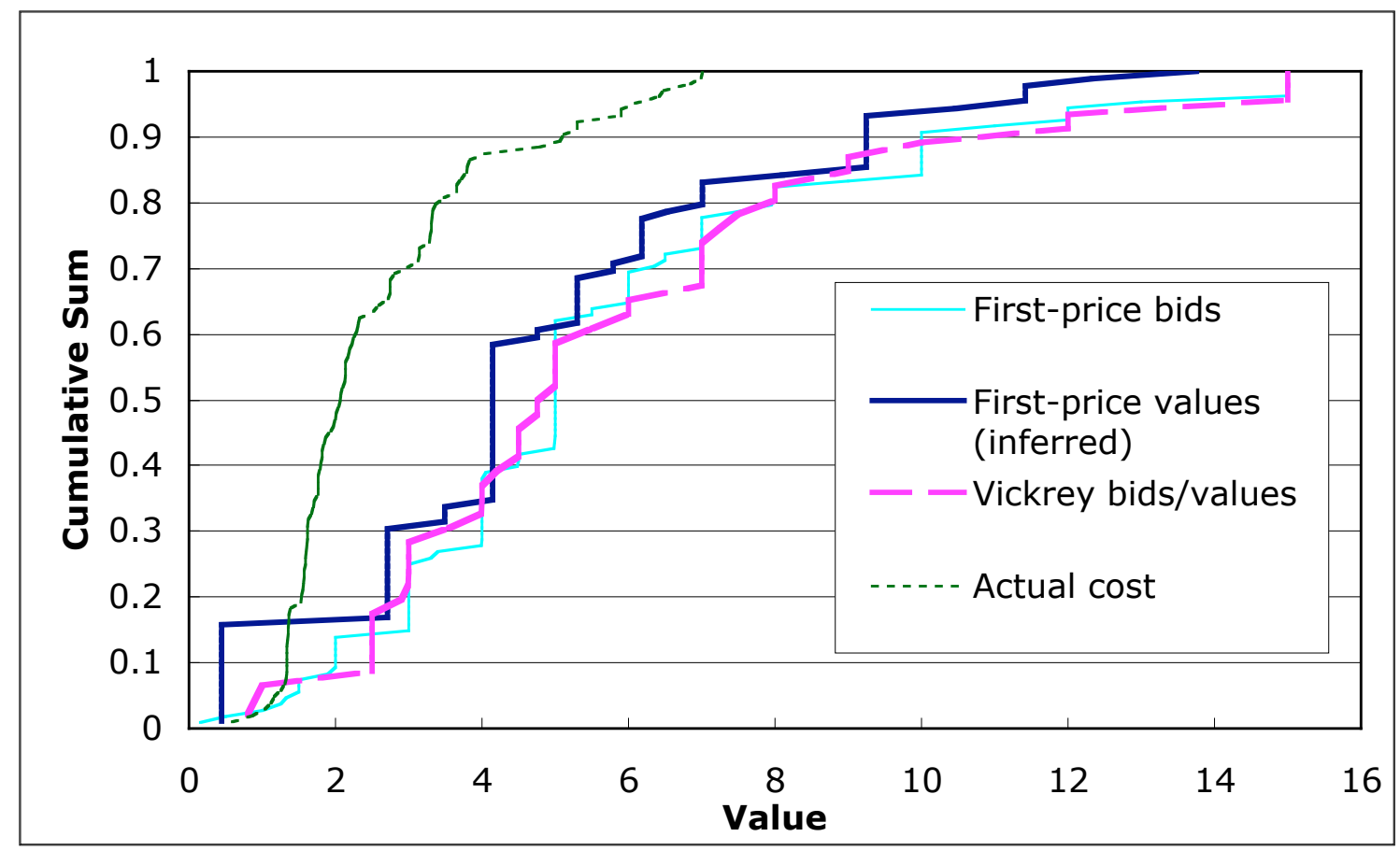

Figure 6c. Bid and inferred value distributions, second merger stage.

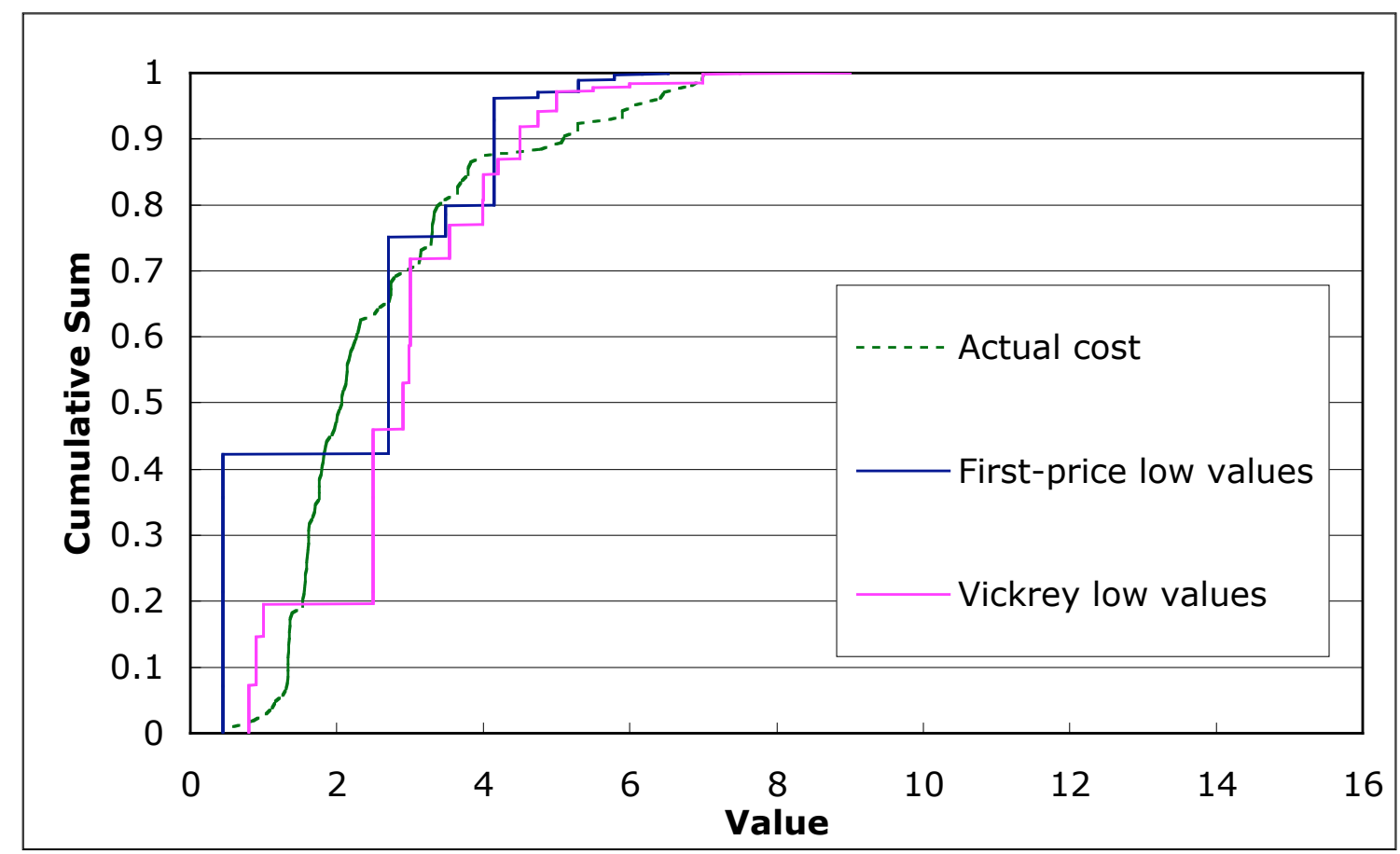

Figure 6d. Distributions of lowest inferred values and Vickrey bids, second merger stage. 
winner's curse: As Figure 6d shows, the bootstrapped distributions of low values for both the Vickrey and first-price treatments are very close to the distribution of actual costs. ${ }^{25}$

It is possible that subjects had trouble estimating the performance of the mixed group because they did not know how many of the same people would be returning to the mixed group for the second merger phase. A mixed group that retained its original members could use the code developed in the first merger stage, whereas a group with a lot of new members would need to create new code. In fact, only one mixed group remained intact in both phases. On average, about 1.8 of the 4 players in the original mixed group were replaced in the second merger stage. Learning effects were strong despite large turnover in the group membership from the first to the second merger phase.

Taken together, the two merger stages illustrate a common underestimation of the effect of structural changes. In the first stage, the lowest bidders systematically underestimate how much earnings will suffer when groups are mixed. But in the second stage, the overestimate the earnings decline — or put differently, they underestimate the improvement from the first stage to the second.

\section{Conclusion}

This study used simple artificial firms to study the development of organizational code, and what happens when firms with different codes merge. The firms' task is to name target pictures from a set, by developing natural language descriptions of the pictures - the "code"-which enable an observer to know which of many pictures was a target. Code use of

\footnotetext{
${ }^{25}$ Although K-S tests indicate that the distributions of low values are significantly different from actual costs ( $\mathrm{p}=0.000$ for both treatments), these tests are affected by the large vertical gaps caused by the bootstrapping procedure and the deviations are small in magnitude.
} 
this sort is like an organization where one person sees a situation or object clearly and must convey it to another person (like police dispatching, journalism or a busy restaurant kitchen). Good code is short and distinctive, because firms are penalized for going slowly and for choosing the wrong pictures. The goal was to learn about development of code, and whether employees could accurately judge how difficult mergers would be because of "cultural conflict" due to differences in code and familiarity. The experiments do not attempt to recreate all the complexities of naturally-occurring organizations. We simply tried to take one element of firms which can be created and measured, and has economic value, and study some of its properties.

The experimental sessions began with students in separate six-person groups on the UCLA and Caltech campuses, creating code for pictures of their own campuses. After a common training phase, the mergers were created by asking subjects how much they would demand to be paid to join a mixed four-person group, with two people from their own-campus group, and two others from the opposite campus. This gives us a measure of how well the subjects think the mergers will go, and also sorts them into mixed (i.e., merger) and unmixed groups endogenously.

Not surprisingly, the mixed groups were slower than the unmixed groups and made more mistakes. Guesses about the performance of the mixed groups, and bids in an incentivecompatible Vickrey auction, underestimated the difficulty of the merger. First-price bids priced the merger difficulty accurately, but are also likely to be biased upward by rational strategic inflation. To correct for this we used an econometric procedure to infer unobserved valuations from bids. The procedure basically takes a bidding function, which maps a value onto a bid, and runs the process in reverse, inferring what unobserved value must have led to an observed bid. The one study that applied this procedure to experimental data (where inferred values and actual 
values can be compared) found a rather accurate correspondence, after adjustment for riskaversion. This procedure shows that the values inferred from all first-price bids are rather accurate guesses of mixed group earnings differentials, as are Vickrey bids on the whole. However, the lowest bidders - those who actually join the mixed groups - are systematically too optimistic. We consider this an "organizational winner's curse," in which the most optimistic organization members will be most willing to make structural changes, and are too optimistic even when the average person is accurate.

Estimates of the mixed group's earnings switched from being overly optimistic in the first merger stage to being a little too pessimistic in the second merger stage. Estimates seemed to reflect a belief that the mixed group's performance had flattened out and would not improve in the second merger stage, although it did.

Inaccurate guesses in both stages are also consistent with anchoring effects. Participants seemed to extrapolate from the experience in the previous phase to the next phase, even though they were clearly instructed about the structural adjustment between phases. The reversal in the first and second stages also means people are not being irrational or optimistic in general-instead, those who participate in the changes do not have rational expectations about the impact of the change. The fact that subjects are much more accurate in the second stage, however, indicates a process of learning.

\section{Future Research}

One line of future research is alternative mechanisms for sorting employees into the merged firm. In our design employees had to be paid to join the merger, but an alternative is to require employees to pay to stay in an unmixed group (corresponding to having to incur relocation or switching costs to stay in their "old job"). Another line of research is turnover: A 
merger can be intended to trim duplicated human resources from the two merging firms, but in practice the best workers often leave rather than the worst ones. Richer structures in which managers can pick and choose who stays or goes, and workers can choose whether to stay or go, could look for these selection effects and their impact.

Future studies could create firms around a different kind of expertise. The subjects in this study were "experts" on a topic they would not expect members of the other group to know anything about. Those who entered the mixed group therefore knew that members from the other school would not understand if they named their own campus buildings by names like "Bunche" or "Millikan." The curse of knowledge was unlikely to play a large role in subjects' descriptions of the pictures or in their valuations for the merger. However, it could have a much more pronounced role if the original firms are composed of experts on areas that others might also know about. For example, one group might see pictures of famous artwork while the other sees pictures of famous movie scenes. When the groups merge, members might assume they can still use proper names, only to be shocked that some people do not know which image "Waterlilies" refers to or which film is "Casablanca." Creating these truly expert groups would require more extensive training, or pre-screening of subjects by their expertise, but would capture a stronger "curse of knowledge" among experts who cannot imagine that others won't understand their codes.

A common problem in mergers is that employees from one firm are marginalized. Even when firms merge as "equals," one often takes the dominant role and attempts to impose its culture on members of the other firm. (See Weber and Camerer, 2003, for an example of dominance in the Daimler-Chrysler "merger of equals.") Using the picture-naming paradigm, we could see if one firm imposes its code on the other when there are a disproportionate number 
of people from each original group, or a longer history, and study the manner in which it does this. Members of the dominant firm might create their own code for pictures that the other firm is familiar with and they may not explain their code to the new members. They might also try to train the smaller firm on their code, as we witnessed in some sessions involving a person who was unfamiliar with the campus.

Weber, Rick, and Camerer (2004) also study managerial structures and response to change (new situations and new employees). They find that rotating managers improves performance but impairs response to change. One could also study "hypercode" (how short do codes become with very long training?), and the role of emotions, humor and memory in code formation and transmission with time interruptions and organizational turnover (cf. Heath and Seidel, undated).

Any of these ideas could be examined by slightly altering the flexible paradigm used in this study. Although we cannot capture all the intricacies of culture in simple experiments, this paradigm allowed us to examine one important facet of culture and create precise measures to test our hypotheses on the cultural difficulties involved in mergers. 


\section{References}

Arrow, Kenneth J. (1974) The Limits of Organization. New York: W.W. Norton and Company.

Andrade, Gregor, Mark Mitchell, and Erik Stafford. (2001) New evidence and perspectives on mergers. Journal of Economic Perspectives, 15(2), 103-120.

Bajari, Patrick and Ali Hortacsu. (2005) Are structural estimates of auction models reasonable?: Evidence from experimental data. Journal of Political Economy, 113(4), 703-741.

Camerer, Colin, George Loewenstein, and Martin Weber. (1989) The curse of knowledge in economic settings: An experimental analysis. The Journal of Political Economy, 97(5), 1232-1254.

Crémer, Jacques. (1993) Corporate culture and shared knowledge. Industrial and Corporate Change, 2(3), 351-386.

, Luis Garicano, and Andrea Prat. (January 2004) Codes in organizations. CEPR Discussion Paper No. 4205. http://ssrn.com/abstract=500913

Gilovich, Thomas, Victoria Husted Medvec, and Kenneth Savitsky. (1998) The illusion of transparency: Biased assessments of others' ability to read one's emotional states. Journal of Personality and Social Psychology, 75(2), 332-346.

Grether, David M., Charles R. Plott, Daniel B. Rowe, Martin Sereno, and John M. Allman. (June 2004) Mental processes and strategic equilibration: An fMRI study of selling strategy in second price auctions. Caltech Social Science Working Paper 1189.

Griffin, D.W. and L. Ross. (1991) Subjective construal, social inference, and human misunderstanding. In M.P. Zanna (Ed.), Advances in Experimental Social Psychology (Vol. 24), 319-359. San Diego, CA: Academic Press.

Guerre, Emmanuel, Isabelle Perrigne, and Quang Vuong. (2000) Optimal nonparametric estimation of first-price auctions. Econometrica, 68(3), 525-574.

Heath, Chip and Victor Seidel. (Undated) Language as a coordinating mechanism: How linguistic memes help direct appropriate action. Working paper, http://www.si.umich.edu/ICOS/Linguisticmemes4.2.pdf

Kagel, John H. (1995) Auctions: A survey of experimental research. In John H. Kagel and Alvin E. Roth (Eds.), The Handbook of Experimental Economics. Princeton, NJ: Princeton University Press. 
Klein, Alec. (2003) Stealing Time. New York: Simon and Schuster.

Kreps, David M. (1990) Corporate culture and economic theory. In James E. Alt and Kenneth A. Shepsle (Eds.), Perspectives on Positive Political Economy. Cambridge: Cambridge University Press.

Li, Tong, Isabelle Perrigne, and Quang Vuong. (2002) Structural estimation of the affiliated private value auction model. RAND Journal of Economics, 33(2), 171-193.

Ravenscraft, David J. and F.M. Scherer. (1987) Life after takeover. The Journal of Industrial Economics, 36(2), 147-156.

, _ (1989) The profitability of mergers. International Journal of Industrial Organization, 7, 101-116.

Rose, Frank. (2003) The civil war inside Sony. Wired Magazine, Issue 11.02.

Schein, Edgar H. (1985) Organizational Culture and Leadership. San Francisco: JosseyBass. . (1990) Organizational culture. American Psychologist, 45(2), 109-119.

Steels, Luc. (2003) Evolving grounded communication for robots. Trends in Cognitive Sciences, 7(7), 308-312.

Sudarsanam, P.S. (1995) The Essence of Mergers and Acquisitions. London: Prentice Hall.

Walsh, James P. (1988) Top management turnover following mergers and acquisitions. Strategic Management Journal, 9, 173-183. and J.W. Ellwood. (1991) Mergers, acquisitions, and the pruning of managerial deadwood. Strategic Management Journal, 12, 201-217.

Weber, Roberto A. and Colin F. Camerer. (2003) Cultural conflict and merger failure: An experimental approach. Management Science, 49(4), 400-415.

, Scott Rick, and Colin F. Camerer. (May 2004) The effects of organizational structure and codes on the performance of laboratory "firms." Working Paper.

Wernerfelt, Birger, (2004) Organizational languages. Journal of Economics and Management Strategy, 13(3), 461-472. 
Appendix 1: Additional graphs.

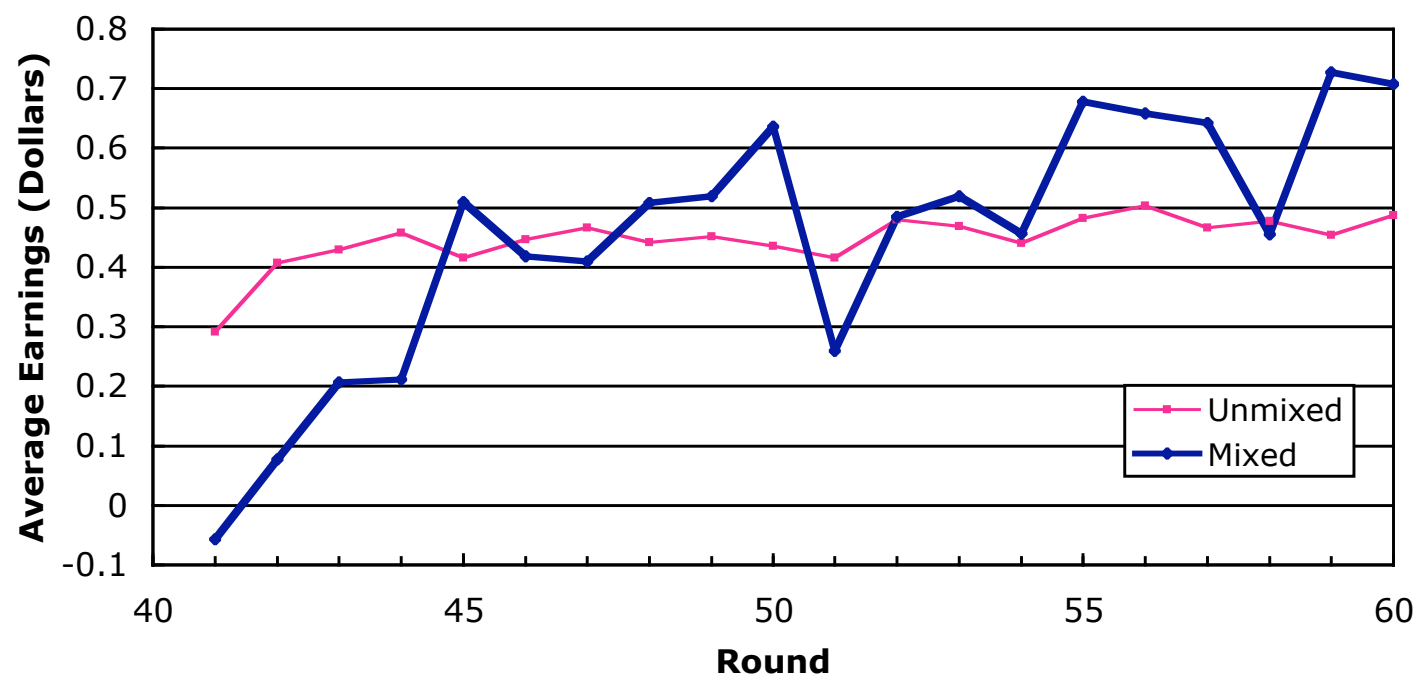

Figure A1. Average completion time by round (all sessions pooled).

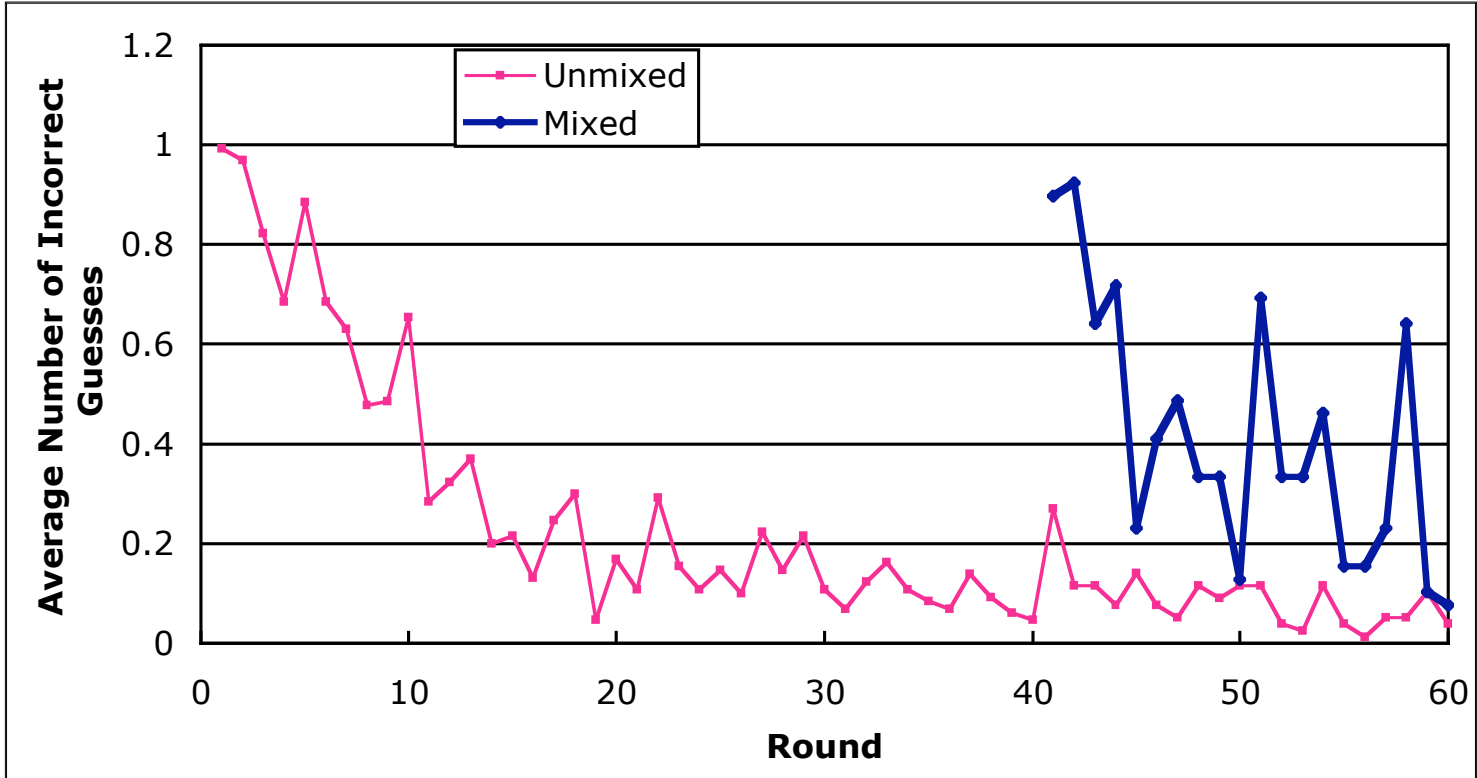

Figure A2. Average number of incorrect guesses by round (all sessions pooled). 


\section{Appendix 2: Value Inference Procedure}

This appendix describes how we made use of the structural procedure of Guerre, Perrigne, and Vuong $(\mathrm{GPV}, 2000)$ to estimate the unobserved values of bidders in the first-price auction treatments. The focus here is on the application of the technique for the type of auction we used; see GPV for details about the technique itself.

The GPV procedure uses the distribution of bids in an auction to estimate the distribution of values. Note that since we used a "procurement" auction, "values" are in fact valuations for remaining in the unmixed group instead of joining the mixed group. In other words, the values we want to infer are each bidder's perceived cost of joining the mixed group. We will assume that each bidder $i$ 's valuation $v_{i}$ is private information that is independent and identically distributed with $\operatorname{cdf} F(\cdot)$ and pdf $f(\cdot)$, which has support $[\underline{v}, \bar{v}]$, with upper bound $\bar{v}=20{ }^{1}$ If a bidder has either the lowest or the second lowest bid in her group, she is placed in the mixed group and gets utility $b_{i}-v_{i}$; otherwise, she gets 0 . We denote the symmetric equilibrium bidding function as $b=s(v)$.

The expected profit of a bidder is her gains from winning, $b_{i}-v_{i}$, times the probability of winning. In our setup, the probability of winning is the sum of the probability of having the lowest bid and the probability of having the second-lowest bid (i.e. bidding higher than only one other bid). We can also think of this as the probability of having a bid less than or equal to the second lowest of all other bids. To maximize profit, then, a bidder solves the following:

$$
\max _{b} E\left[(b-v) \mathbb{1}\left(b \leq B_{2}\right) \mid v\right]=\max _{x} \int_{x}^{\bar{v}}[s(x)-v] f_{y_{2} \mid v}\left(y_{2} \mid v\right) \mathrm{d} y_{2},
$$

where $B_{2}=s\left(y_{2}\right)$ is the second lowest of others' bids.

Since subjects bid in groups of 6 , each bidder would need to bid below or tie the second lowest of 5 other bids. Therefore, $f_{y_{2} \mid v}\left(y_{2} \mid v\right)=20 F\left(y_{2}\right)\left[1-F\left(y_{2}\right)\right]^{3} f\left(y_{2}\right)$. The first order

\footnotetext{
${ }^{1}$ A more general analysis could assume value affiliation, as in Li, Perrigne, and Vuong (2002). We are unable to use the procedure for affiliated private values because it requires a much larger amount of data.
} 
condition at $x=v$ is:

$$
-(s(x)-v) \cdot 20 F(x)[1-F(x)]^{3} f(x)+\int_{x}^{\bar{v}} s^{\prime}(x) \cdot 20 F\left(y_{2}\right)\left[1-F\left(y_{2}\right)\right]^{3} f\left(y_{2}\right) \mathrm{d} y_{2}=0
$$

Plugging in $x=v$ and simplifying, we get:

$$
1=(s(v)-v) \cdot \frac{20 F(v)[1-F(v)]^{3} f(v)}{-4[1-F(v)]^{5}+5[1-F(v)]^{4}} \cdot \frac{1}{s^{\prime}(v)}
$$

This gives an expression to infer $\mathrm{F}(\mathrm{v})$ from $\mathrm{s}(\mathrm{v})$. Following GPV, we use the distribution of bids to obtain estimates of values. We denote the distribution and density of bids by $G(\cdot)$ and $g(\cdot)$, respectively. For every $b \in[\underline{b}, \bar{b}]=[s(\underline{v}), \bar{v}], G(b)=P(\tilde{b} \leq b)=P\left(\tilde{v} \leq s^{-1}(b)\right)=$ $F\left(s^{-1}(b)\right)=F(v)$, since $b=s(v) . G(\cdot)$ is continuous with support $[\underline{v}, s(\bar{v})]$ and density $g(b)=f(v) / s^{\prime}(v)$.

Using $b=s(v), F(v)=G(s(v))$, and $f(v)=g(s(v)) \cdot s^{\prime}(v),(1)$ becomes:

$$
v=b-\left[\frac{-4[1-G(b)]^{5}+5[1-G(b)]^{4}}{20 G(b)[1-G(b)]^{3} g(b)}\right]
$$

Using this equation, we can estimate $\hat{v}$, the inferred values, by getting estimates for $G(b)$ and $g(b)$.

To estimate $\hat{g}(b)$, we considered all bids less than or equal to $20 .^{2}$ We smoothed the set of bids using an Epanechnikov kernel. The bandwidth was chosen so that the density would have a single peak but not be overly smooth. ${ }^{3}$ The cumulative distribution function, $\hat{G}(b)$, was calculated from the point estimates of $\hat{g}(b)$.

The estimates $\hat{G}(b)$ and $\hat{g}(b)$ were plugged into equation (2). The points used for the kernel smoothing served as "b" in this equation. This provided a value estimate for each point in the kernel smoothing. The actual bids were then rounded up to match these points

\footnotetext{
${ }^{2}$ This excluded bids above the 97th percentile in the first merger stage of the first price treatment, and we excluded bids above 20 in further analysis for the sake of consistency.

${ }^{3}$ The bandwidth was 1.40 for the first merger stage and 0.99 for the second.
} 
to find the inferred value corresponding to each bid. 